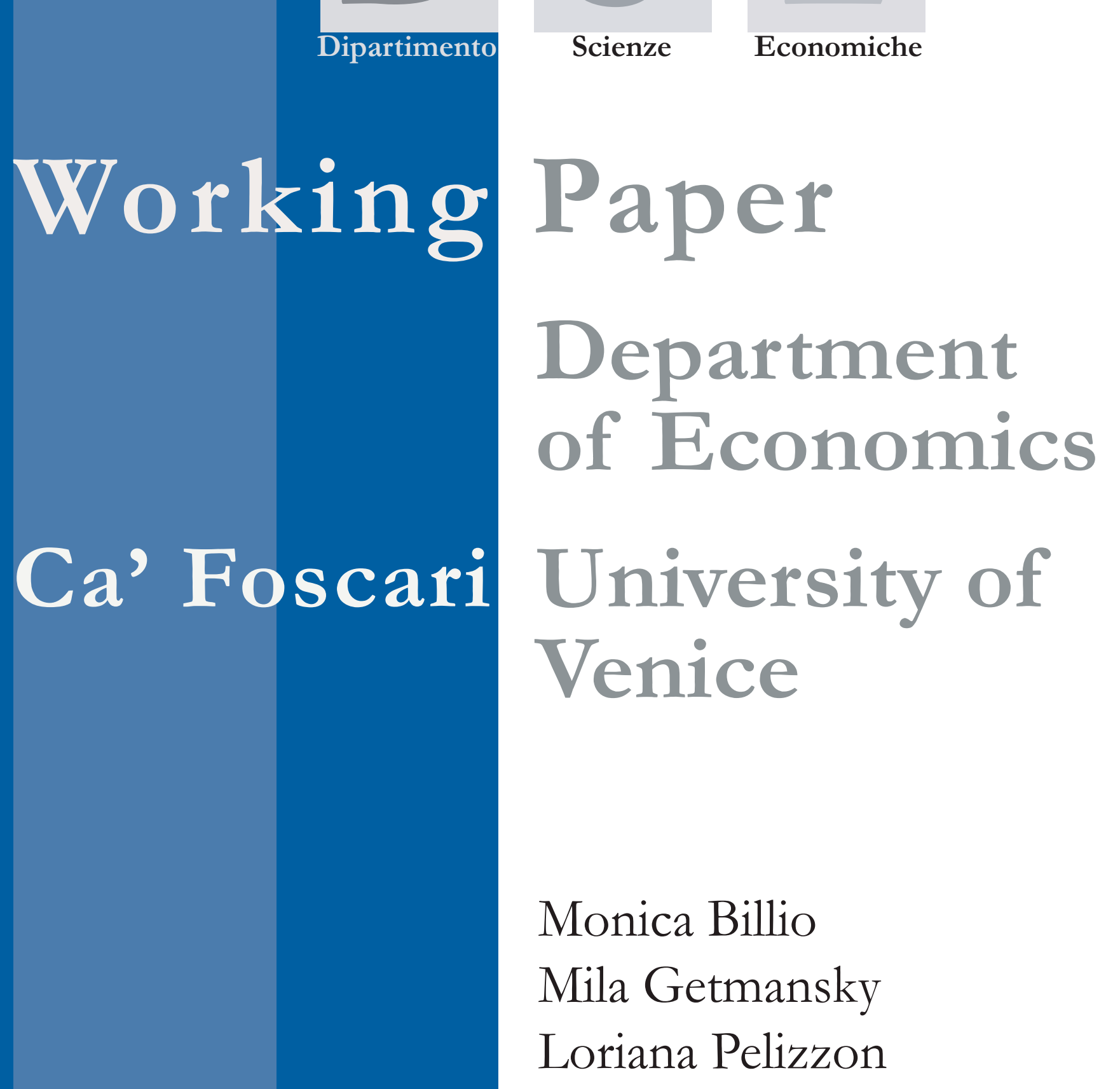

Phase-Locking and Switching Volatility in Hedge Funds 


\title{
Phase-Locking and Switching Volatility in Hedge Funds
}

\author{
Monica Billio \\ University of Venice and SSAV, Scuola Studi Avanzati in Venezia \\ Mila Getmansky \\ Isenberg School of Management, University of Massachusetts \\ Loriana Pelizzon \\ University of Venice and SSAV, Scuola Studi Avanzati in Venezia
}

November 2006

\begin{abstract}
This article aims to investigate the phase-locking and switching volatility in the idiosyncratic risk factor of hedge funds using switching regime beta models. This approach allows the analysis of hedge fund tail event behavior and in particular the changes in hedge fund exposure to various risk factors potentially related to liquidity risk, conditional on different states of the market. We and that in a normal state of the market, the exposure to risk factors could be very low but as soon as the market risk factor captured by the S\&P500 moves to a down-market state characterized by negative returns and high volatility, the exposure of hedge fund indexes to the S\&P500 and especially to other risk factors changes significantly presenting evidence of phase-locking. We further extend the regime switching model to allow for non-linearity in residuals and show that switching regime models are able to capture and forecast the evolution of the idiosyncratic risk factor in terms of changes from a low volatility regime to a distressed state that are not directly related to market risk factors.
\end{abstract}

\section{Keywords}

Hedge Funds; Risk Management; Regime-Switching Models, Liquidity

\section{JEL Codes}

G12, G29, C51

\author{
Address for correspondence: \\ Monica Billio \\ Department of Economics \\ Ca' Foscari University of Venice \\ Cannaregio 873, Fondamenta S.Giobbe \\ 30121 Venezia - Italy \\ Phone: (++39) 0412349170 \\ Fax: (++39) 0412349176 \\ e-mail: billio@unive.it
}

This Working Paper is published under the auspices of the Department of Economics of the Ca' Foscari University of Venice. Opinions expressed herein are those of the authors and not those of the Department. The Working Paper series is designed to divulge preliminary or incomplete work, circulated to favour discussion and comments. Citation of this paper should consider its provisional character.

The Working Paper Series is availble only on line (www.dse.unive.it/pubblicazioni) For editorial correspondence, please contact: wp.dse@unive.it
Department of Economics

Ca' Foscari University of Venice

Cannaregio 873, Fondamenta San Giobbe

30121 Venice Italy

Fax: ++390412349210 


\section{Introduction}

The last decade has seen an increase in the number of hedge funds and availability of hedge fund data both on individual hedge funds and on hedge fund indexes. Unlike mutual funds, hedge funds engage in dynamic strategies, use leverage, employ derivatives and have nonlinear payoffs. Further, hedge funds are known for their "opportunistic" nature of trading and a significant part of their returns arise from taking state-contingent bets.

Along with spectacular returns, hedge funds have experienced colossal losses: Long Term Capital Management hedge fund and other Fixed Income strategy funds in 1998, Long/Short Equity and Global Macro strategies in 2002, losses in the Convertible Bond Arbitrage strategy in 2005 and the collapse of Amaranth Multi-Strategy hedge fund in September 2006. All these losses were sudden, unanticipated events characterized by low probability. Chan Getmansky, Haas and Lo (2005) describe this phenomenon as phase locking ${ }^{1}$. Due to the phase-locking phenomenon, correlations between hedge funds and markets change, making mean-variance allocations sub-optimal in crises conditions.

In this paper we show that this characteristic behavior for hedge funds cannot be explained by standard linear factor models. We demonstrate how a switching regime beta approach, that accounts for "short-lived" and "infrequent" events, can accurately capture non-linear exposure of hedge funds to various factors, and specifically, to precisely estimate tail risk exposure. Switching regime beta models are able to capture changes in market volatilities in different states as well as phase-locking phenomenon (i.e., a sudden change in correlations between hedge funds and risk factors). Forbes and Rigobon (2002) find that cross-market correlations are biased if not adjusted for switching market volatility. Therefore, hedge fund exposures will be biased if not corrected for switching market volatilities.

Moreover, the use of regime-switching models of hedge funds is appropriate as many hedge funds implement regime-switching strategies. For example, a long-short strategy hedge fund is more likely to be long equity during up-markets and short equity during down-markets (Alexander and Dimitriu (2005)). Goetzmann, Ingersoll, Spiegel and Welch (2006) describe that hedge funds game their strategies according to past returns by using leverage and options. Mitchell and Pulvino (2001) show that merger (risk) arbitrage managers generate returns that resemble a short put, short call payoff. Agarwal and Naik (2000a, 2004) show that returns for several hedge fund strategies resemble option payoffs (on both calls and puts). Goetzmann et al. (2006) find that "dynamic manipulation taken in order to influence returns, induces time variation into the return distribution". Therefore, it is important

\footnotetext{
1 "Phase-locking" behavior is borrowed from natural sciences, where otherwise uncorrelated actions suddenly become synchronized.
} 
to consider different factor loadings for hedge fund strategies during different regimes of a market. The authors find that the relationship between the Sharpe ratio or portfolio return and underlying market return has a natural logarithm function ${ }^{2}$, i.e., Sharpe ratio and portfolio return are bounded above and have an infinite left tail. They find that the optimal strategy for hedge funds might be selling out-of-the-money puts and calls, ensuring that during normal and up markets, hedge fund managers obtain a positive cash flow, and have a large exposure in extreme negative events. Therefore, hedge fund factor exposure is time-varying and should be estimated with regime-switching model with three regimes (up-market, down-market and normal).

It is important to understand and model time-varying risk exposures, considering switching volatility in the market, for various strategies. Moreover, it is imperative to obtain reliable estimates for predicted exposures of hedge fund returns to various market risk factors in different market volatility regimes and potential exposure to latent variables. There is still a limited understanding of the real non-linear exposure to risk factors of the different hedge funds strategies and the role played by liquidity risk. In this paper, in line with the asset pricing perspective proposed by Bekaert and Harvey (1995), we analyze the exposure of hedge fund indexes with a factor model based on regime switching, where non-linearity in the exposure is captured by factor loadings that are state dependent. Our approach is able to capture the switching volatility of market risk factor and characterize its returns by three different regimes: normal, down-market and up-market. ${ }^{3}$ The state dependent factor loadings are able to capture the exposure of the hedge fund to the risk factors in these different states. Our factor loadings estimates are unbiased as the approach takes into consideration volatility switching in the market risk factor (as suggested by Forges and Rigobon (2002)).

As we show in the paper, the use of beta switching regime models allows us to capture and analyze phase-locking, hedge fund tail behavior and switching volatility of the idiosyncratic risk factor. More specifically, with our analysis we uncover five main phenomena with corresponding results.

First, our investigation of the S\&P returns endogenously highlights three S\&P regimes (or states): a regime characterized by both high S\&P 500 returns and low S\&P 500 volatility that we call the "up-market", a regime with low S\&P 500 expected returns and high S\&P 500 volatility ("down-market") and a "normal (middle)" regime characterized by "middle"

\footnotetext{
${ }^{2}$ The maximal Sharpe ratio return has a lognormal distribution bounded above and with an infinite left tail. Return is assumed to be lognormally distributed (Goetzmann et al. (2006)).

${ }^{3}$ Our definition of up-market and down-market is a definition encompassing both means and standard deviations. It should not be confused with notation used by Mathur, Pettengill and Sundaram (1995), where up-market and down-market are defined as positive and negative, respectively, realizations of the difference between realized market return and risk free rate.
} 
expected S\&P 500 mean and "middle" S\&P 500 volatility". We also calculate transition probabilities of moving from one market regime to another. We find that the "normal" regime is quite persistent and the probability of maintaining this state is $98 \%$. Interestingly, we find that the "down-market" regime has 0 probability of transitioning into a "normal regime"; if it does transition, it transitions to the "up-market" regime (with $26 \%$ probability). Finally, we find the "up-market" regime to be quite transitory, having only $28 \%$ probability of maintaining the state.

Second, the use of regime-switching models of hedge funds is appropriate as many hedge funds implement regime-switching strategies (Goetzmann et al. (2006)). We are able to uncover different hedge fund exposures in different market states of the world.

Another aspect that we are able to highlight using the regime-switching methodology is a phase-locking property of hedge funds. The link between a hedge fund and risk factors, due to dynamic strategies employed by hedge funds, is characterized by a phase-locking model. For example, most of the time factor loadings might be very low or zero for some particular risk factors, but suddenly factor loadings can become very large. In such a scenario, simple linear models with linear factor loadings show that hedge fund exposure to risk factors is negligible, so we are not capturing a small-probability down-market event that would lead to the phaselocking behavior. As we show, the regime-switching approach is able to capture changes in factor loadings depending on the state of the market and exposure to risk factors that, most of the time are negligible and are not captured by linear models. Phase-locking phenomenon describes a link that is absent most of the time, but is present in low-probability downmarket events (i.e., hedge fund returns have a greatly increased exposure to these factors during market down-turn: UMD, VIX, Credit spread and Large-Small).

The fourth reason of the relevance of using switching regime beta models to investigate hedge funds exposure is that liquidity risk is relevant for hedge funds and liquidity shocks are highly episodic and tend to be preceded by or associated with large and negative asset return shocks, whereby liquidity risk is rendered a particularly non-linear phenomenon. Indeed, as stressed by Acharya and Schaefer (2006) prices in capital markets exhibit different regimes. In a normal regime, intermediaries, including hedge funds, are well capitalized and liquidity effects are minimal. In the "illiquidity" regime usually related to market down-turns, intermediaries are close to their risk or collateral constraints and there is a "cash-in-the-market" pricing (Allen and Gale $(1994,1998))$. In this framework, derivatives and complex struc-

\footnotetext{
${ }^{4}$ The expected returns and volatilities for each state are endogenously defined from the data. Section 4 and Table 2 show that the return pattern of S\&P 500 could be easily captured with three regimes, where up-market regime has a mean of $5.79 \%$ and a relatively low volatility $1.52 \%$. The normal regime has a mean of $0.85 \%$ and a volatility of $2.49 \%$. The down-market regime captures market downturns and has a mean of $-2.02 \%$ and a volatility of $4.51 \%$.
} 
tured products investors like hedge funds are more likely to be the marginal price setters and therefore more largely affected by the "illiquidity" regime. With our switching regime model, we are indeed able to capture the non-linear phenomenon of liquidity shocks and their effects on hedge funds returns.

In our analysis we investigate several risk factors indicated in the literature as able to capture liquidity risk in developed and emerging markets such as Large-Small (FamaFrench Factor), Credit Spreads, MSCI Emerging Market Debt and Equity and we found that the exposure to these risk factors are mostly characterized by zero exposure during the normal state and significant exposure during market downturns. Nevertheless, given the large collinearity between market risk, asset liquidity risk and hedge fund funding liquidity risk, we are not able to distinguish statistically the relative return impacts of funding liquidity, liquidity risk and market risk. However, we find some evidence that the total effect of these risks matters for hedge fund returns.

The fifth reason for using the switching regime beta model is that it allows for nonlinearity in residuals. We are able to investigate the dynamic evolution of the idiosyncratic risk factor in terms of changes from a low volatility regime to a high volatility state that is independent of observable risk factors. The switching regimes captured by our model in the idiosyncratic risk factor can be a proxy for an opportunistic risk taking. Indeed, as we know from practitioners, there is a persistency in risk taking conditional on the hedge fund performance that may change quickly as soon as hedge fund expectations change. Moreover, the switch in volatility of the idiosyncratic risk factor may also capture hedge fund exposure to "latent" risk factors that change randomly over time. These latent risk factors could again capture liquidity risk not directly related to the capital market. Specifically, Brown and Spitzer (2006) conjecture that idiosyncratic volatility can capture liquidity risk not related to the market risk. Our analysis shows that the idiosyncratic risk factor of hedge funds is largely characterized by changes from a low volatility regime to a high volatility state that are not directly related to market risk factors. We further explored the probability that all hedge fund strategies exhibit idiosyncratic risk in a high volatility regime. This could be interpreted as a proxy measure for contagion between different hedge fund strategies. Specifically, we calculate the joint probability of being in a high volatility state for all hedge funds. We find that the joint probability jumps from approximately 0\% in May, 1998 to $4 \%$ in June, 1998 to $13 \%$ in July, 1998 to $96 \%$ in August of 1998. It started to subside in October, 1998. The peak in the joint probability coincides with the liquidity crisis precipitated by the collapse of LTCM. The results suggest that the LTCM crisis not only affected market risk factors, but also, after controlling for market and other factor exposures, it affected idiosyncratic volatility of hedge funds. This provides evidence that even after accounting 
for market and other factor exposures, the LTCM crisis precipitated contagion across the hedge fund industry. This result is consistent with the one provided by Boyson, Stahel and Stulz (2006) where by using extreme events, they found contagion among different hedge fund styles.

Our approach is different from percentile or extreme returns analysis because factor loadings depend on an underlying state variable that has an intuitive interpretation in terms of market regimes and where down-market period may also face positive returns. Our approach also differs from the Asset-Based Style Factors (ABS) (Fung and Hsieh (2001)) approach because we do not need to define a priory the strategy that hedge funds may follow, but in line with the classical Sharpe-style analysis approach (Sharpe, (1992)), we leave the data to highlight the dynamic exposure to risk factors.

Our analysis shows that market risk factor exposures are different but not necessarily directly related to a particular option strategy, but are more related to a mixture of strategies based on options. In the spirit of Fung and Hsieh (2001) and Agarwal and Naik (2004), we are suggesting a more flexible approach, where a whole range of options strategies can be captured, and we do not have to be limited to several specific exogenously-defined options. Our analysis indeed confirms that hedge funds are using different regime-switching strategies and change their exposure based on different market conditions.

The rest of the paper is organized as follows. Related literature review is presented in Section 2. In Section 3 we define a series of beta switching regime models that can be used to analyze the different hedge fund style indexes. Section 4 describes the data and presents results for the one factor and multifactor beta switching regime models. Section 5 uncovers additional phase locking exposures and presents an analysis on omitted factors. Section 6 presents analysis on evolution of the idiosyncratic factor. Section 7 provides robustness checks. We compare our approach to OLS, asymmetric beta and threshold models. We also adjust for potential illiquidity and smoothing in the data and check that regime-switching approach is applicable to individual hedge funds as well as indexes. Section 8 concludes.

\section{Literature Review}

The tremendous increase in the number of hedge funds and availability of hedge fund data has attracted a lot of attention in the academic literature that has been concentrated on analyzing hedge funds styles (Fung and Hsieh (2001) and Mitchell and Pulvino (2001)), performance and risk exposure (Fung and Hsieh (1997), Brealey and Kaplanis (2001), Edwards and Caglayan (2001), Agarwal and Naik (2004), Bali, Gokcan and Liang (2005), Gupta and 
Liang (2005), and Schneeweis, Karavas, and Georgiev (2002)), liquidity, systemic risk and contagion issues (Getmansky et al. (2004), Chan et al. (2006) and Boyson, Stahel and Stulz (2006)). All of the above studies find that risk return characteristics of the hedge fund strategies are nonlinear, that hedge funds implement dynamic strategies and exhibit nonlinear and non-normal payoffs. The analysis of risk exposure is based on three main approaches. The first approach is based on the classical linear factor model applied to mutual funds. The second approach is introduced by Fund and Hsieh (1997), based on a predetermined structure on the risk factors (quintiles analysis or extreme event analysis). The third approach is based on option-like payoffs called also Asset-Based Style Factors (ABS-Factors) introduced by Fung and Hsieh (2001) and Agarwal and Naik (2004).

Currently, no parametric models ${ }^{5}$ exist in the hedge fund literature that explain a timevarying hedge fund risk exposure without imposing exogenous definition of different states of the world (i.e. up or down markets, declines or rallies), specific non-linear structures or the use of option-like approach.

We differentiate from previous literature because our aim is not to investigate the strategies that hedge funds are following, our model is strategy-independent. We analyze risk factor exposure that can be both generated by specifics of hedge funds strategies or by some latent factors affecting the assets held by hedge funds. Therefore, the fact that each hedge fund is not implementing the same strategy within the same hedge fund category makes our model more desirable to use. Moreover, we endogenously estimate conditional distributions of market returns in each market regime, derive the likelihood of transition from one state to another and calculate time-varying hedge fund risk exposures for each of the regimes.

Fung and Hsieh (1997) emphasize limitations of models, including their own, that put structure on the risk factor. However, given that hedge fund data became available only in $1994^{6}$, Fung and Hsieh (1997) had to resort to building models with a predetermined structure on the risk factor, such as conducting a quintile analysis. Given current availability of more than 10 years of monthly data, we can conduct a thorough analysis on hedge fund returns that could not be done before due to data limitations. In a completely flexible approach, in the same spirit as Fung and Hsieh (1997), we measure the exposure of the hedge fund indexes to risk factors in different states, i.e. when the market risk factor is facing normal returns and volatility, or when the market is facing low returns and high volatility, or some other states where the states are not exogenously imposed but endogenously determined

\footnotetext{
${ }^{5} \mathrm{Li}$ and Kazemi (2006) propose a nonparametric GARCH $(1,1)$ model to study asymmetry in conditional correlations.

${ }^{6} \mathrm{CSFB} /$ Tremont database for hedge fund indexes starts in January, 1994. Individual hedge funds were available prior to 1994; however, the database is only adjusted for survivorship bias starting January 1994.
} 
by the model.

This aspect is extremely important because we avoid the problem of exogenously fixing the regimes (or state thresholds) and we are able to provide more information in terms of the likelihood of being in one regime or the other. This last aspect allows us to calculate the likelihood for hedge funds switching from one exposure to another.

The importance of using regime-switching models is well established in the financial economics literature after Bekaert and Harvey's (1995) regime switching asset pricing model, Ang and Bekaert's (2002) and Guidolin and Timmerman (2006) regime switching asset allocation model and Billio and Pelizzon's (2005) analysis of contagion among markets. Moreover, regime-switching models have been successfully applied to constructing trading rules in equity markets (Hwang and Satchell (2000), equity and bond markets (Brooks and Persand (2001)), and foreign exchange markets (Dueker and Neely (2004)). The closest to our paper implementation is by Chan, Getmansky, Haas and Lo (2005) where regime switching models are applied to the CSFB/Tremont hedge fund indexes to analyze the possibility of switching from a normal to a distressed regime in the hedge fund industry.

Our approach differs from the previous work since we use a switching regime beta model to measure the exposure of hedge funds indexes to different regimes that characterize market risk factors. Such exposure cannot be measured with the simple switching regime model used by Chan et al. (2005) because they do not analyze the relationship with the market risk factor and the regimes of the market risk factor. Accounting for regime-switching in market returns is very important for optimal investment decision by an investor. For example, using a sample of mutual funds, Tiwari (2006) found 341 basis points per month utility loss from ignoring regime switching for an investor who has perfect prior confidence in the 4-factor Carhart model. We conjecture that for hedge funds that have more non-linearities and asymmetric exposure to market factors compared to mutual funds, not accounting for regime switching in market factors will lead to even a greater economic loss. By using regime-switching models, investors can identify and select hedge funds and hedge fund indexes with favorable market exposure in each regime and in particular in market downturns. They will also be more informed about transition probabilities between different regimes and probabilities of being exposed to several market factors.

Moreover, an important question in hedge fund literature is to understand risk exposure of hedge funds especially in extreme states of the world. Pierre Saint-Laurent (2005) in a recent article said that it is very important to understand returns and risks in market downturns or under distress. With our analysis we are able to shed a light on this issue and verify if there are some states where the different hedge fund strategies would be exposed to the same factors indicating the possibility of a systematic risk among the hedge fund family. 


\section{Theoretical Framework}

Linear factor models such as the capital asset pricing model (CAPM) and the arbitrage pricing theory (APT) have been the foundation of most of the theoretical and empirical asset pricing literature. Formally, a simple one factor model applied to hedge fund index returns could be represented as:

$$
R_{t}=\alpha+\beta I_{t}+\omega u_{t}
$$

where $R_{t}$ is the return of a hedge-fund index in period $t, I_{t}$ is a factor, for example, $S \& P 500$ in period $t$, and $u_{t}$ is IID.

In this model, we can identify the exposure of hedge fund returns to a factor $I$. Unfortunately this theory constrains the relation between risk factors and returns to be linear. Therefore it cannot price securities whose payoffs are nonlinear functions of the risk factors, i.e. hedge fund returns which are characterized by the implementation of dynamic strategies. For this reason we propose a more flexible and complete model for capturing this feature: a switching regime model.

A Markov switching-regime model is a model where systematic and un-systematic events may change from the presence of discontinuous shifts in average return and volatility. The change in regime should not be regarded as predictable but as a random event. More formally, the model could be represented as:

$$
\begin{aligned}
R_{t} & =\alpha+\beta\left(S_{t}\right) I_{t}+\omega u_{t} \\
I_{t} & =\mu\left(S_{t}\right)+\sigma\left(S_{t}\right) \epsilon_{t}
\end{aligned}
$$

where $S_{t}$ is a Markov chain with $n$ states and transition probability matrix $\mathbf{P}$. Each state of the market index $I$ has its own mean and variance and the same applies to the returns of the hedge fund index. More specifically, the hedge fund mean returns and volatility are related to the states of the market index and are defined by the parameter $\alpha$ plus a factor

loading, $\beta$, on the conditional mean of the factor, where $\beta$ could be different conditional on a state of a factor risk.

For example, if $n=3$ (state labels are 0,1 or 2), the model can be represented as follows: 


$$
R_{t}=\left\{\begin{array}{l}
\alpha+\beta_{0} I_{t}+\omega u_{t} \text { if } S_{t}=0 \\
\alpha+\beta_{1} I_{t}+\omega u_{t} \text { if } S_{t}=1 \\
\alpha+\beta_{2} I_{t}+\omega u_{t} \text { if } S_{t}=2
\end{array}\right.
$$

where the state variable $S$ depends on time $t$, and $\beta$ depends on the state variable:

$$
\beta\left(S_{t}\right)= \begin{cases}\beta_{0} & \text { if } S_{t}=0 \\ \beta_{1} & \text { if } S_{t}=1 \\ \beta_{2} & \text { if } S_{t}=2\end{cases}
$$

and the Markov chain $S_{t}$ (the regime switching process) is described by the following transition probability matrix $\mathbf{P}$ :

$$
\mathbf{P}=\left[\begin{array}{lll}
p_{00} & p_{01} & p_{02} \\
p_{10} & p_{11} & p_{12} \\
p_{20} & p_{21} & p_{22}
\end{array}\right]
$$

with $p_{02}=1-p_{00}-p_{01}, p_{12}=1-p_{10}-p_{11}$ and $p_{22}=1-p_{20}-p_{22}$. The parameters $p_{00}$, $p_{11}$ and $p_{22}$ determine the probability of remaining in the same regime. This model allows for a change in the variance of returns only in response to occasional, discrete events. Despite the fact that the state $S_{t}$ is unobservable, it can be estimated statistically (see for example Hamilton $(1989,1990))$.

Our specification is similar to the well-known "mixture of distributions" model. However, unlike standard mixture models, the regime-switching model is not independently distributed over time unless transition probabilities $p_{i j}$ are equal to $1 / n$, where $\mathrm{n}$ is the number of states. Indeed, one key aspect of the switching regime model is that if the volatility has been efficiently characterized with different parameters for different periods of data, it will be probable that in the future the same pattern will apply. As the switching regime approach accounts for "short-lived" and "infrequent" events, it provides an accurate representation of the left-hand tail of the return distribution.

The advantage of using a Markov chain as opposed to a "mixture of distributions" is that the former allows for conditional information to be used in the forecasting process. This 
allows us to: (i) fit and explain the time series, (ii) capture the well known cluster effect, under which high volatility is usually followed by high volatility (in presence of persistent regimes), and (iii) generate better forecasts compared to the mixture of distributions model, since switching regime models generate a time conditional forecast distribution rather than an unconditional forecasted distribution.

The Markov switching model is more flexible than just using a truncated distribution approach as proposed for hedge funds by Asness, Krail and Liew (2001) and Boyson, Strahel and Stulz (2006) as at each time $t$, we have a mixture of one or more normal distributions, and this mixture changes every time. Using the truncated distribution will lead to nonparametric estimation, where the down state of the market is exogenously imposed, and it is hard to make inferences about beta forecast and conditional expectations. Instead, we use a parametric model to help us to separate the states of the world. We will be able to infer time-varying risk exposures of hedge funds, make forecasts, calculate transitional probabilities from one state to another and calculate conditional expectations.

Our approach is in the spirit of Agarwal and Naik (2004) but rather than using ABS factors to capture dynamic strategies, we allow for dynamic factor loadings with different betas. In this way we capture, with a formal model, the idea of Fung and Hsieh (1997) to separate factors into different quintiles based on historical performance and try to access the exposure of hedge fund returns to factors in each of the quintiles. Moreover, the use of quintiles implies the exogenous definition of states. On the contrary, we let the model to determine the states. Moreover, our formal model allows us to forecast future behavior.

More specifically, once parameters are estimated, forecasts of changes in regime can be readily obtained, as well as forecasts of $\beta_{t}$ itself. In particular, because the $k$-step transition matrix of a Markov chain is simply given by $\mathbf{P}^{k}$, the conditional probability of the regime $S_{t+k}$ given date- $t$ data $\mathcal{R}_{t} \equiv\left(R_{t}, R_{t-1}, \ldots, R_{1}\right)$ takes on a particularly simple form when the number of regimes is 2 (regime 0 and 1 ):

$$
\begin{aligned}
\operatorname{Prob}\left(S_{t+k}=0 \mid \mathcal{R}_{t}\right) & =\pi_{1}+\left(p_{00}-\left(1-p_{11}\right)\right)^{k}\left[\operatorname{Prob}\left(S_{t}=0 \mid \mathcal{R}_{t}\right)-\pi_{1}\right] \\
\pi_{1} & \equiv \frac{\left(1-p_{11}\right)}{\left(2-p_{00}-p_{11}\right)}
\end{aligned}
$$

where $\operatorname{Prob}\left(S_{t}=0 \mid \mathcal{R}_{t}\right)$ is the probability that the date- $t$ regime is 0 given the historical data up to and including date $t$ (this is a by-product of the maximum-likelihood estimation procedure). More generally, the conditional probability of the regime $S_{t+k}$ given date- $t$ data is 


$$
\begin{aligned}
\operatorname{Prob}\left(S_{t+k}=0 \mid \mathcal{R}_{t}\right) & =\mathbf{P}^{k \prime} \mathbf{a}_{t} \\
\mathbf{a}_{t} & =\left[\operatorname{Prob}\left(S_{t}=0 \mid \mathcal{R}_{t}\right) \quad \operatorname{Prob}\left(S_{t}=1 \mid \mathcal{R}_{t}\right) \quad . . \operatorname{Prob}\left(S_{t}=n \mid \mathcal{R}_{t}\right)\right]^{\prime}
\end{aligned}
$$

Using similar recursions of the Markov chain, the conditional expectation of $\beta_{t+k}$ can be readily derived as:

$$
\begin{aligned}
\mathrm{E}\left[\beta_{t+k} \mid \mathcal{R}_{t}\right] & =\mathbf{a}_{t}^{\prime} \mathbf{P}^{k} \boldsymbol{\beta} \\
\boldsymbol{\beta} & \equiv\left[\begin{array}{lll}
\beta_{0} & \beta_{1} & . . \beta_{n}
\end{array}\right]^{\prime}
\end{aligned}
$$

Time-varying betas can be easily determined using equation 11 by assuming that $\mathrm{k}=0$. This gives us the framework for analyzing time-varying risk exposures for hedge funds for different factors. Moreover, this framework can be used to calculate expected time-varying risk exposures for hedge funds for various factors, by setting $\mathrm{k}$ to be more than 0 . For example, if $\mathrm{k}=1$, we can calculate the evolution of expected one-month beta exposures to different factors.

The previous model described in equations 2 and 3 could be extended in several ways. For example, we propose a regime switching model with non-linearity in residuals and in the intercept coefficient:

$$
\begin{aligned}
R_{t} & =\alpha\left(Z_{t}\right)+\beta\left(S_{t}\right) I_{t}+\omega\left(Z_{t}\right) u_{t} \\
I_{t} & =\mu\left(S_{t}\right)+\sigma\left(S_{t}\right) \epsilon_{t}
\end{aligned}
$$

In this model, additional non-linearities are captured by the intercept and the residuals. $Z_{t}$ proxies for all other non-linearities not captured by non-linearities between hedge fund and the risk factor $I$.

Usually there are more than one factor that affect hedge fund returns. Our switching regime beta model could be easily extended to a multifactor model.

The first extension is a model in the same spirit as of Agarwal and Naik (2004) with a 
non-linear exposure to S\&P 500 and a linear exposure to other risk factors. More formally:

$$
\begin{aligned}
R_{t} & =\alpha\left(Z_{t}\right)+\beta\left(S_{t}\right) I_{t}+\sum_{k=1}^{K} \theta_{k} F_{k t}+\omega\left(Z_{t}\right) u_{t} \\
I_{t} & =\mu\left(S_{t}\right)+\sigma\left(S_{t}\right) \epsilon_{t}
\end{aligned}
$$

where $\theta_{k}$ is the linear factor loading of the hedge fund index on the $k$-th risk factor and $F_{k t}$ is the return on the $k$-th risk factor at time $t$.

However, this model does not consider the possibility that the exposure to the other factors could be affected by the regime that characterizes the S\&P 500. To capture this feature, we propose a multifactor beta switching model with non-linearity in residuals:

$$
\begin{aligned}
& R_{t}=\alpha\left(Z_{t}\right)+\beta\left(S_{t}\right) I_{t}+\sum_{k=1}^{K} \theta_{k}\left(S_{t}\right) F_{k t}+\omega\left(Z_{t}\right) u_{t} \\
& I_{1 t}=\mu\left(S_{t}\right)+\sigma\left(S_{t}\right) \epsilon_{t}
\end{aligned}
$$

This model allows us to detect the exposure of hedge fund indexes to different factors conditional on the state that characterizes the market index factor that in our empirical analysis is represented by the S\&P500.

Goodness-of-fit for our non-linear models is measured using McFadden's (1974) pseudo$R^{2}$ approach. In this approach, the unrestricted (full model) likelihood, $L_{U R}$ is compared to the restricted (constants only) likelihood, $L_{R}$, as follows

$$
\text { Pseudo }-R^{2}=1-\frac{\log L_{U R}}{\log L_{R}}
$$

Pseudo- $R^{2}$ has been used by Boyson, Stahel and Stulz (2006) to compare different hedge fund risk models. 


\section{Empirical Analysis}

\subsection{Data}

For the empirical analysis in this paper, we use aggregate hedge-fund index returns from CSFB/Tremont database from January 1994 to March 2005. The CSFB/Tremont indexes are asset-weighted indexes of funds with a minimum of $\$ 10$ million of assets under management, a minimum one-year track record, and current audited financial statements. An aggregate index is computed from this universe, and 10 sub-indexes based on investment style are also computed using a similar method. Indexes are computed and rebalanced on a monthly frequency and the universe of funds is redefined on a quarterly basis. We use net-of-fee monthly excess return (in excess of LIBOR). This database accounts for survivorship bias in hedge funds (Fung and Hsieh (2000b)). Table 1 describes the sample size, S\&P $500 \beta$, annualized mean, annualized standard deviation, minimum, median, maximum, skewness and kurtosis for monthly CSFB/Tremont hedge-fund index returns as well as for the S\&P 500 .

[INSERT Table (1) about here]

For our empirical analysis, we evaluate the exposure of hedge fund indexes to the market index, S\&P 500; therefore, we only concentrate on hedge fund styles that either directly or indirectly have S\&P 500 exposure. For example, we concentrate on directional strategies such as Dedicated Shortseller, Long/Short Equity and Emerging Markets as well as nondirectional strategies such as Distressed, Event Driven Multi-Strategy and Risk Arbitrage.

Categories greatly differ. For example, annualized mean of excess return for the Dedicated Shortseller category is the lowest: $-6.48 \%$ and the annualized standard deviation is the highest at the $17.63 \%$. Distressed has the highest mean of $7.32 \%$, but relatively low standard deviation: $6.69 \%$. The lowest annualized standard deviation is reported for the Equity Market Neutral strategy at $2.94 \%$ with an annualized mean of $4.08 \%$. Hedge fund strategies also show different third and fourth moments. Specifically, non-directional funds such as Event Driven Multi-Strategy, Risk Arb and Convertible Bond Arb all have negative skewness and high kurtosis. The exception is for the Equity Market Neutral strategy which has a low positive skewness and kurtosis. Directional strategies such as Dedicated Shortseller, Long/Short Equity have positive skewness and small kurtosis. Emerging Markets has a slight negative skewness of -0.65 and a small kurtosis. The market factor is characterized by high annualized excess return of $5.52 \%$ and high standard deviation of $15.10 \%$ during our sample 
period. Moreover, the distribution of the factor is far from normal and is characterized by negative skewness.

\subsection{Beta Switching Regime Models}

\subsubsection{One factor model}

In this section we first verify the presence of the S\&P 500 regimes in the data, and then analyze the exposure of different hedge fund indexes to the different states of the S\&P500 market index by implementing the model described in equation 3 .

The identification of the optimal number of regimes in Markov switching models cannot be obtained through likelihood ratio tests because such tests are problematic since the usual regularity conditions are not fulfilled under the null hypothesis (some parameters are unidentified and the information matrix is singular). Hence the asymptotic null distribution of the likelihood ratio test statistic is not a $\chi^{2}$ one. Hansen (1992) proposed a test which does not suffer from this problem, but his test procedure is computationally burdensome and only delivers p-values which are an upper bound for the true p-values. A computationally less demanding test procedure is discussed in Garcia (1998), but this method is theoretically less attractive than Hansen's (1992) since it overlooks the problem of the singular information matrix. An alternative way of circumventing these difficulties would be to use critical values and/or p-values from a bootstrap approximation to the null distribution of the likelihood ratio test statistic, as suggested by McLachlan (1987) for independent mixture models. It should be borne in mind, however, that the asymptotic correctness of such bootstrap tests has not been established yet and is far from obvious.

More recently, Poskitt and Chung (1996), Francq and Zakoan (1998, 2001) and Zhang and Stine (2001) have shown that weakly stationary processes generated by various Markovswitching models admit linear autoregressive moving-average (ARMA) representations. Since the order of these ARMA representations is generally a function of the number of Markov regimes, Poskitt and Chung (1996), Krolzig (1997) and Zhang and Stine (2001) have argued that the state dimension of the hidden Markov chain can be determined by estimating the order of the equivalent ARMA representation of the observable process. Zhang and Stine (2001) used simulation experiments to examine the properties of the proposed method as a means of identifying the state order in Markov switching models with no dynamics and compared them with procedures based on the AIC and BIC. In the same spirit, Psaradakis and Spagnolo (2003) investigate the properties of alternative procedures that exploit the ARMA representation as well as procedures that are based on optimization of complexity-penalized 
likelihood measures (see also Leroux, 1992).

Since all these procedures are computationally burdensome and outside the objectives of the paper, we preferred to follow the financial intuition and the literature ${ }^{7}$ that well recognize the presence of normal times, rolling-up or down-turns times in the returns of the equity market, to test various models and finally we decided on three regimes. The results of the estimation are shown in Table 2.

[INSERT Table (2) about here]

Table 2 shows that the return pattern of S\&P 500 could be easily captured with three regimes, where regime 0 has a mean of $5.79 \%$ and a relatively low volatility $1.52 \%$. We denote this regime as the up-market state, which has a very low probability of remaining in the same regime next month: $P_{00}=28 \%$. The regime 1 has a mean statistically different than zero and equal to $0.85 \%$ and a volatility of $2.49 \%$ and we call it a normal state. This is a persistent regime, and the probability of remaining in it is $98 \%$. The last regime captures market downturns and has a mean of $-2.02 \%$ and a volatility of $4.51 \%$. The probability of remaining in this regime is $74 \%$.

The model estimation allows us to infer when S\&P 500 was in one of the three regimes for each date of the sample using the Hamilton filter and smoothing algorithm (Hamilton, 1994). Figure 1 depicts the resulting series.

[INSERT Figure (1) about here]

From Figure 1 we observe that in the first part of the sample, the S\&P 500 returns are frequently characterized by the normal regime 1, in particular from July 1994 to December 1996. The period from 1997 through 2003 is characterized mostly by two other regimes: up-market and down-market. This outcome is generated mainly by high instability of the financial markets starting from the Asian down-market in 1997, well captured by regime 2, the technology and internet boom, well captured by regime 0, the Japanese down-market of March 2001, September 11, 2001 and the market downturn of 2002 and 2003, captured mostly by regime 2 . The last part of the sample from 2003 through 2005 is characterized by the normal regime 1 . It is important to note that the three regimes approach does not imply

\footnotetext{
${ }^{7}$ Goetzmann et al. (2006) show that an optimal strategy for hedge funds might be selling out-of-themoney puts and calls, ensuring that during normal and up markets, hedge fund managers obtain a positive cash flow, and have a large exposure in extreme negative events.
} 
simply the split of the data sample into large negative, large positives or close to the mean returns. The regime approach captures periods where the return distribution belongs to large volatility periods characterized by large downturns or more tranquil periods. In all these different regimes we may face positive or negatives returns. This approach is closely compared to an alternative threshold approach where a sample is split into positive and negative returns, following Fung and Hsieh (1997). These two approaches are carefully compared in Section 7. More specifically, the regime switching approach allows us to endogenously determine changes in market returns distributions without exogenously splitting the data into positive and negative returns.

This analysis of the S\&P 500 returns illustrates the ability of regime-switching models to capture changes in return process determined endogenously by the model.

In addition to analyzing the change in the S\&P 500 returns and probability of being in a particular regime, we derive both conditional and unconditional distributions for the S\&P 500 for all three regimes as well as for the total time series.

[INSERT Figure (2) about here]

Figure 2 depicts unconditional distribution of S\&P 500 overall, in down-market, normal and up-market regimes. First, it is worthwhile to notice that during the time period analyzed in the paper, market clearly experienced three distinct regimes: up-market, normal and down-market. Moreover, the total distribution is skewed, and distribution of being in a downmarket state is characterized by fat tails. Figure 2 also depicts conditional distribution of different regimes, conditioned on starting in regime 2, a down-market regime. The resulting total distribution closely overlaps regime 2 distribution, especially in the left tail. Therefore, once in down-market, the market is more likely to stay in down-market (74\%), and both conditional regime 2 and total distribution are fat-tailed.

[INSERT Figure (3) about here]

Figure 3 shows conditional distributions of S\&P 500 overall, in down-market, normal and up-market regimes first conditional on an up-market regime and second conditional on a normal regime. Interestingly, conditioned on being in an up-market, there is a certain probability of staying in an up-market (28\%), but there is also a large left-tail probability of moving to a down-market (67\%). It looks like the up-market regime is often transitory, followed by a down-market. The probability of going to a normal regime after an up-market 
is small (5\%). Conditional on being in a normal regime, the total distribution is almost identical to the conditional probability of a normal regime. Therefore, if a market is in the normal regime, it is more likely to stay this way (98\%). The conditional distributions for all regimes are very close to normal in this case. Nevertheless, there is a small probability of $2 \%$ of moving to an up-market regime that is more likely $(67 \%)$ followed by a down-market.

Overall, the results confirm that during the period of January, 1994 to March, 2005, S\&P 500 was clearly characterized by three separate regimes. In the paper, we are interested in clearly understanding the exposure of each hedge fund strategy to the market in all these regimes. In other words, we are interested in finding the exposure of hedge fund returns to all parts of this distribution. Moreover, most studies analyzed exposure of hedge funds given a normal regime. Using the results in Figure 3, it is clear that this approach underestimates the tail of the distribution and thus biases hedge fund market risk exposure.

After having characterized the process for the S\&P 500 we analyze the exposure of different hedge fund strategies to different S\&P 500 regimes. The analysis is based on the model presented in equation 13 and results are shown in Table 3.

\section{[INSERT Table (3) about here]}

We find different factor loadings with respect to the S\&P 500 regimes for almost all hedge funds indexes. The only exception is the Convertible Bond Arbitrage strategy. More specifically, for Equity Market Neutral we find a positive exposure in the regime 0, i.e. when the market is rolling up. The exposure is zero in normal times and when the market is mostly characterized by a downturn. This result is in line with the fact that the Market Neutral strategy can neutralize the effects of normal movements of the market, but when the market is suddenly moving to another regime facing a phase-locking phenomenon, the exposure becomes positive. Regarding the other more directional strategies (Dedicated Shortseller and Long/Short Equity), we do find significant exposures to the S\&P 500 regimes, but again the factor loadings vary a lot for different regimes. In particular, Dedicated Shortseller shows a large negative exposure of -1.26 to $\mathrm{S} \& \mathrm{P} 500$ in normal times. This relationship is maintained for the down-market period; however, the exposure is reduced in half for the up-market state of the market. Long/Short Equity strategy aims to go both long and short on the market during the normal regime. Our analysis shows that the exposure to the market during the normal regime is three times as high as the exposure during the other two regimes. There is, therefore, an attempt of this strategy to reduce the exposure to the market down-turns, but the exposure remains still positive, as shown in Table 3. 
The Emerging Market strategy shows a peculiar positive exposure mostly when the market is characterized by the down-market state and is relatively large in normal time. The result of the large exposure on market down-turns is intuitive since many emerging markets do not allow short-selling. Therefore, the exposure result is similar to writing a put option on the S\&P index.

The other three strategies are related to the Event Driven categories. The exposures to the S\&P 500 are positive and quite similar in different states of the market, especially for the Event Driven Multi-Strategy that has a slightly higher exposure during the market downturn. Distressed security strategy presents a larger exposure in normal times. The Risk Arbitrage Strategy presents a positive exposure in the normal regime and when the market is rolling up and an almost zero exposure in the down-market regime. Nevertheless, other risk factors play a role as important as the S\&P 500 in characterizing the time-varying hedge fund exposure. This aspect is investigated in the next section with a multifactor model.

Moreover, using regime switching framework allows us to calculate time-varying risk exposure of hedge funds implied by the data, i.e. time-varying betas with respect to various factors including S\&P 500 for various hedge fund strategies. So far, this has not been accomplished in previous research due to predominant use of non-parametric models in explaining hedge fund risks. Time-varying betas can be easily determined using equation 11 by assuming that $\mathrm{k}=0$. This gives us the framework for analyzing time-varying risk exposures for hedge funds for different factors. Time-varying market risk betas are depicted for several hedge fund strategies in Figures 4 and 5.

[INSERT Figure (4) about here]

[INSERT Figure (5) about here]

First, note that the market exposure changes over time for all strategies, confirming that hedge funds are implementing dynamic strategies. Figure 4 depicts evolution of market betas for Hedge fund index, Long/Short equity and Risk arbitrage strategies. In all cases, starting the middle of 2003, exposure of these strategies to the market dramatically increased. For example, for the Combined Hedge fund index, the forecasted exposure in April, 2004 was 0.07, seemingly market-neutral; however, exposure in March, 2005 increased to 0.37, which is a significant positive market exposure. For the same time period, the exposure of the Long/Short equity increased from 0.20 to 0.64 , more than 3-fold. Risk arbitrage strategy exposure more than doubled during this time period to 0.14 . It is interesting to note that in all these categories, the market beta is cyclical: it was increasing from 1994 through 1997, 
then it abruptly dropped and stayed low for 7 years, and started to increase in 2003. Similar behavior is also observed for Convertible bond arbitrage, Distressed, and Dedicated short seller (for this strategy, the exposure is increasing in the negative direction). This cyclical behavior in market beta can be largely attributed to the changes in market regimes. For example, as was found in Figure 1, we observe that in the first part of the sample, the S\&P 500 returns are frequently characterized by the normal regime 1, in particular from July 1994 to December 1996. The period from 1997 through 2003 is characterized mostly by two other regimes: up-market and down-market. The last part of the sample from 2003 through 2005 is characterized by the normal regime.

Figure 5 shows a different story compared to results depicted in Figure 4. Here, we show strategies which have a recent decrease either in volatility of the market beta or decrease in the market beta estimate implied from the data. For example, for the Event driven multi-strategy, the exposure decreased from 0.17 in 2003 to 0.14 in March, 2005. For the Emerging markets category, since 1997 to 2003, the exposure fluctuated a lot, from 0.2 to 0.5. However, since the beginning of 2003, up to the end of the data sample, the market exposure equilibrated at 0.41 . The same behavior is observed for Equity market neutral strategy, where from 1997 to 2003, the exposure fluctuated from 0.03 to 0.09, equilibrating to 0.07 starting the middle of 2003.

Moreover, this framework can be extended to calculating expected hedge fund exposures to different factors one-month from now, 6-months from now, 1-year from now and so on. Our flexible approach can allow us to calculate expected time-varying betas for $\mathrm{t}+\mathrm{k}$ periods by using specification 11 .

The above analysis has shown that the exposure to S\&P index changes through time. Nevertheless, overall the market exposure seems to be not so strong and in the down-turn state only the Emerging Market index seems to present a large exposure to the S\&P.

\subsubsection{Multifactor model}

\section{Multifactor model with non-linear exposure only to S\&P 500}

As discussed above, other factors are affecting hedge fund index returns and this calls for the use of a multifactor framework. We begin with a comprehensive set of risk factors that will be candidates for each of the risk models, covering stocks, bonds, currencies, commodities, emerging markets, momentum factor and volatility. These factors are presented in Table 4. They are also described by Chan, Getmansky, Haas and Lo (2005). We use step-wise approach to limit the final list of factors for our analysis. Using a combination of 
statistical methods and empirical judgement, we use these factors to estimate risk models for the 8 hedge fund indexes. In all our analysis, hedge fund returns, S\&P 500, USD, Lehman Government Credit, Gold, MSCI Emergent Markets Bond Index, MSCI Emergent Market Stocks Index and Momentum French factor are used in excess of LIBOR returns.

[INSERT Table (4) about here]

We first consider the model presented in equation (15) and the results for this model are contained in Table 5. Here, we are considering linear factors: Large-Small, Value-Growth, USD, Lehman Government Credit, Term Spread, change in VIX, Credit Spread, Gold, MSCI Emergent Markets Bond Index, MSCI Emergent Market Stocks Index, Momentum French factor and non-linear exposure to different states of the S\&P 500.

\section{[INSERT Table (5) about here]}

The number of factors $F$ selected for each risk model varies from a minimum of 2 for Risk Arbitrage to a maximum of 8 for the Event Driven Multi-Strategy, not including the S\&P 500 index. This pattern is plausible because the Event Driven Multi-Strategy by definition includes a broad set of strategies hence a broad array of risk factors is needed to capture the variation in this category versus other categories.

The statistical significance of the factor loadings on S\&P 500 conditional on the different regimes is almost the same as the one obtained in the previous analysis with only the $\mathrm{S} \& \mathrm{P}$ 500 risk factor. The only main difference is the exposure of the Distressed strategy in the up-market state to the S\&P500 and the exposure of the Emerging Markets strategy in the up-market and normal states to the S\&P 500. This indicates that the analysis performed above is robust to the inclusion of other factors that may affect hedge index returns.

Regarding the Fama and French factor: Large Minus Small, we observe that this factor is relevant for almost all the hedge fund index strategies, the only exception is Equity Market Neutral. The exposure to the Large Minus Small factor is negative for almost all the Hedge funds indexes (the only exception is the Dedicated Shortseller) suggesting that returns of these hedge indexes resemble those achieved by going long on small stocks and short on large stocks (as shown already by Agarwal and Naik (2004) and Chan et al. (2005)). Another potential explanation is that this factor is capturing liquidity risk as highlighted by Amihud (2002) and Acharya et al. (2004). We will consider this aspect later. 
The hedge fund exposure to another Fama and French factor: Value Minus Growth is positive for Convertible Bond Arbitrage, Dedicated Shortseller, Distressed, Event Drive Multi-Strategy and Risk Arbitrage.

A detailed analysis of other factors is presented for each hedge fund strategy. The list of factors and hedge fund exposures to these factors is unique for each hedge fund strategy; therefore, we are analyzing them one by one for each hedge fund strategy.

Convertible Bond Arbitrage

This strategy is characterized by investing in a company bond while shorting the common stock of the same company. Positions are designed to protect the principal from market moves. As it was shown before in one-factor setting, the convertible bond arbitrage strategy is not correlated with S\&P 500 moves in all regimes (Table 3). However, in the multi-factor setting, we find a slight positive exposure of 0.04 to the S\&P 500 in the up-market. There are two potential explanations for this effect. First, as market moves up, hedge fund managers do not have adequate time to hedge the stock exposure by shorting more stock. Second, the arbitrageurs would like to capitalize on the up-market move, and will not hedge perfectly in order to make more money. The strategy is doing better when returns on small and value stocks are high. Clearly, because the strategy is designed to profit from upward fixed income moves, the strategy is positively related to the Lehman Government Credit bond index returns. The most significant coefficient in the regression is -1.77 effect of Credit Spread. Clearly, when credit spread increases, liquidity decreases and there is a low demand for lowcredit securities. Convertible Bond Arbitrage funds mostly hold low-credit securities. At the time of high credit spreads, brokers request a higher hair-cut fee to obtain more leverage. Cost of funding goes up, therefore, the return on the strategy decreases.

\section{Dedicated Shortseller}

This strategy is geared to maintain net short position at all times. The highest net negative market exposure is during the normal regime of the market. Dedicated Shortseller strategy is doing well when large and value indexes are performing well. The strategy also has a positive exposure to the US Dollar and MSCI Emergent Bond returns. Similar to the Convertible Bond Arbitrage strategy, this strategy has a negative exposure (-0.73) to the Credit Spread. However, the exposure is about twice as small: -0.73 compared to -1.77 . It makes sense, as credit spread increases, the cost of shorting a stock increases, thus, decreasing the returns of the strategy.

$\underline{\text { Emerging Markets }}$ 
This strategy involves both equity and fixed income investing around the world. The net market exposure is positive in all states of the world (insignificant in the normal state of the world), which makes sense because many emerging markets do not allow or have limited short selling and do not offer viable futures or derivative products with which to hedge market exposure. Especially, during crises periods, the exposure is highly positive (0.39) due to inability to hedge this exposure. The strategy is performing well when small stocks are doing better than large stocks, which can be attributed to liquidity premium. The effect of the US Dollar is positive and significant (0.27). Stronger US Dollar increases demand for foreign goods, thus, boosting emerging markets economy. Since many emerging markets funds invest in fixed income, it makes sense that the relationship between the Lehman Government Credit index returns and the strategy returns is positive and significant (0.57). Moreover, an increase in the term spread has a positive effect (0.65) on the strategy returns. The strategy is doing well when the yield curve is sloping up (the exposure to Term-Spread is 0.65). The Emerging Markets strategy has a big and significant (estimate is 0.21 and t-stat is 6.81) exposure to the MSCI Emergent Stock, which makes sense as this strategy trades directly in this market. Finally, there is a slight positive exposure to the Momentum Factor and Gold.

Equity Market Neutral

The strategy is designed to be market beta neutral, which is confirmed for normal market conditions (0.05 and not significant). However, the strategy is not neutral during up-market times. Managers are not able to timely put market hedges in place, thus, the strategy is positively exposed to upward market movements (0.11). The strategy seems to be marginally exposed to Lehman Government Credit index and MSCIEMS.

\section{Long/Short Equity}

The strategy takes both long and short market positions. During the normal times of the market factor, the exposure is 0.51 and remains almost the same in both down-market and up-market periods. The strategy is doing well when small stocks do well. The strategy is doing well during the low interest rate environment (the exposure to the Lehman Government Credit index returns is positive $=0.23$ ). Generally, the strategy is doing well when the yield curve is flat. So, if long or short-term rates are changing, then the return of the Long/Short Equity strategy decreases as can be seen by a negative coefficient on the term spread (0.30). The exposure to the Credit Spread is -2.27 and very significant, which is consistent with the general preference for small illiquid stocks and increase in stock lending rate in increased credit spread environments. The strategy also benefits from increase in volatility and momentum factor. 


\section{Distressed}

Distressed strategy primarily concentrates on investing in the debt, equity or trade claims of companies in financial distress and generally bankruptcy. There is a modest market exposure during normal times (0.30) and the exposure increases during down-market times. The strategy is doing well when small stocks are outperforming their large counterparts and when value stocks perform better than growth stocks. Because the strategy is also investing in fixed income, it is highly positively correlated with the Lehman Government Credit index returns (0.23). Similar to Convertible Bond Arbitrage, the strategy suffers from increase in credit spreads, as the strategy primarily invests in Distressed, or low-quality and highly illiquid securities. These distressed securities will greatly suffer in liquidity crises. Therefore, compared to all other strategies, the coefficient (-2.69) on Credit Spread for the Distressed strategy is the largest. There is also a slight negative exposure to the MSCI Emergent Bond index.

\section{Event Driven Multi-Strategy}

This subset refers to hedge funds that draw upon multiple themes, including risk arbitrage, distressed securities, and occasionally others such as investments in micro and small capitalization public companies that are raising money in private capital markets. Fund managers often shift assets between strategies in response to market opportunities. Therefore, the market exposure is positive in all market states. The strategy is doing well when small stocks are outperforming large ones. Event Driven Multi-Strategy managers are opportunistic and therefore when US Dollar is stronger, they have more investing power and can take advantage of more investment opportunities. Therefore, the relationship between the US Dollar and strategy returns is 0.32 . There is a positive, but small exposure to change in VIX (0.06). The most significant coefficient in the regression is -2.43 effect of Credit Spread. Clearly, when credit spread increases, liquidity decreases and there is a low demand for low-credit securities. Event Driven Multi-Strategy funds mostly hold low-credit securities. At the time of high credit spreads, brokers request a higher hair-cut fee to obtain more leverage. Cost of funding goes up, therefore, the return on the strategy decreases. The strategy also has a positive exposure to MSCI Emergent Bond and Stock indexes as well as to the Momentum Factor.

Risk Arbitrage

Specialists invest simultaneously in long and short positions in both companies involved in a merger or acquisition. Risk arbitrageurs are typically long the stock of the company being acquired and short the stock of the acquiring company. Market exposure is positive especially in crises periods (0.17), indicating that managers in this strategy take a lot of risk. 
The strategy is correlated with the performance of small versus large stocks $(-0.14)$. There is a small premium to value stocks (0.07).

\section{Multifactor model with non-linear exposure to all factors}

Finally we estimate the multifactor model specified in equation (17) and the results are contained in Table 6. Here, we are considering non-linear exposure to factors: S\&P 500, Large-Small, Value-Growth, USD, Lehman Government Credit, Term Spread, change in VIX, Credit Spread, Gold, MSCI Emergent Markets Bond Index, MSCI Emergent Market Stocks Index and Momentum factor. The three coefficients that we estimate represent the non-linear exposure to the risk factors of the hedge fund indexes in the three states of the S\&P500. Because of the limited dataset we only consider variables that are statistically significant in the previous multifactor linear exposure analysis. Later we relax this assumption and consider the possibility of a non-linear exposure also to other risk factors that were not linked to the hedge fund indexes in the previous linear multifactor analysis (See section 5).

\section{[INSERT Table (6) about here]}

All strategies have exposure to the $\mathrm{S} \& \mathrm{P} 500$ in at least one regime even after accounting for conditional exposure to other risk factors. Generally, we find that the model that accounts for different factors conditional on the state of the market is richer and captures more exposures compared to previous models. Moreover, the model is showing that factor exposure is changing conditional on the state of the market. Moreover, we find that the main risk factor for hedge funds is not necessarily only the market, but the Credit Spread, especially, the effect of the Credit Spread in the negative states of the market. For most of the strategies (except Dedicated Shortseller), the impact of the Credit Spread in the negative market regime on hedge fund index returns is negative, and it is the most negative compared to up-market and normal regimes.

For five out of eight strategies (Convertible Bond Arbitrage, Emerging Markets, Distressed, Event-Driven Multi Strategy and Risk Arbitrage) our results suggests that they tend to hold illiquid and low-credit securities and thus are susceptible to liquidity crises. We find that in all of these strategies, exposure to LS (Large-Small) is negative and highly significant during market downturn. In all these cases the exposure is higher in absolute value compared to the exposure to LS during other market conditions. Actually, for Convertible Bond Arbitrage, Event-Driven Multi Strategy and Risk Arbitrage, the exposure to LS during normal market conditions is negligible. Overall, almost all hedge fund indexes have a 
significant exposure to the Large Minus Small factor in at least two out of three states and especially during market downturn. This result is in line with the potential interpretation of Acharya and Schaefer (2006) that the "illiquidity" regime is usually related to market down-turns. Furthermore, note that LS is the only common factor in the market down-turn for seven out of eight hedge funds strategies and for six out of eight it has the same sign. This result suggests that this variable may potentially capture a common factor in the hedge fund industry.

Moreover, credit spread can also serve as a proxy for illiquidity risk. When credit spread increases, cost of capital increases and investors prefer to invest in more liquid and highquality instruments. Therefore, low-credit illiquid investments suffer. We find a highly negative coefficient on credit spread during down market conditions for Convertible Bond Arbitrage, Long/Short Equity, Distressed and Event-Driven Multi-Strategy. In all of these cases except Distressed, the exposure to credit spread during down market conditions is much higher in absolute terms compared to normal market conditions.

Furthermore, our analysis shows that many factor exposures are characterized by the phase-locking property. For example, the exposure to Lehman Government Credit is negligible for Convertible Bond Arbitrage and Long/Short Equity indexes; however, it becomes highly positive and significant for up and down-market states. The exposure to USD is negligible in the normal state of the market, but becomes highly positive and significant for Dedicated Shortseller and Emerging Markets. Nevertheless, note that the phase locking phenomenon could be produced by dynamic strategies and/or a factor exposure of hedge fund asset portfolio that becomes statistically relevant only in certain states. With our approach we are not able to distinguish among the two phenomena and simply capture the total exposure that arises from both dynamic strategies and asset portfolio non-linear exposures.

Below we consider each strategy separately and address time-varying risk exposures for various factors.

\section{Convertible Bond Arbitrage}

Compared to previous results, the Convertible Bond Arbitrage strategy has a significant positive exposure to the S\&P 500 during up-market times. During normal times and downmarket, there is no exposure because managers typically perfectly hedge market fluctuations. Therefore, during market up turns, the strategy is positively related to the market. The strategy has a positive exposure to credit spread when market is in the normal times (0.87). The spread reflects investor perception relating to how likely the issuing company will be able to make timely interest payments and pay off the principal at maturity. The larger, or wider, the spread, the more concern investors have regarding the issuing company's ability to 
make timely interest payments. During normal times of the market, investors are less worried about the increase in credit spread. However, during crises times, this worry is more sound and the strategy is negatively compensated for having a high credit spread $(-2.67)$. During up-market times of the market, the coefficient on the term spread is -2.10 . We observe this minus sign because convertible bond funds tend to short stock.

\section{Dedicated Shortseller}

This strategy has significant exposure to all factors in different states of the market. The exposure to credit spread in a normal-market period is (-6.42) and positive in both up-market (0.36) and down-market (3.18). The strategy is positively exposed to the MSCIEMD in the down-market and negatively exposed in the normal market.

\section{Emerging Markets}

During up, normal and down states of the market, the effect of term spread is positive and significant $(0.86,0.47$ and 1.40 respectively). In a way, the managers implement a strategy of going long on longer maturity bond and shorting a shorter maturity bond. In crises states of the market, this strategy is very vulnerable to liquidity shocks. If the short-term interest rate is rising, the strategy will lose money in those states. Interestingly, the exposure to the MSCI Emergent Stock is greatly reduced in the down market periods.

\section{Equity Market Neutral}

In the previous analysis on multi-factor model with linear factors, Equity Market Neutral index appears to be linked only to the Lehman Government Credit and MSCI Emergent Bond risk factors. Allowing for non-linearities, we find that the exposure to the MSCI Emergent bond risk factor is positive in the up-market and not significant for other regimes. The exposure to the S\&P 500 is positive and significant for both neutral and up-market and not significant for the down market.

\section{Long/Short Equity}

The exposure to credit spread in a down-market period is (-3.19) and in a normal period is (-1.78), whereas, in an up-market period is (3.66). It can be interpreted that generally Long/Short Equity managers tend to buy low liquidity, low credit rated instruments; however, in the up-market, they quickly adjust their exposure to buying high credit securities. This might make sense because managers tend to take concentrated trades in specific sectors or markets. The change in VIX is positively related to the strategy return in up and normal states of the S\&P 500 .

\section{$\underline{\text { Distressed }}$}


The exposure to credit spread is negative and significant during all regimes of the credit spread, meaning that distressed funds always hold illiquid and low quality securities. This strategy is usually categorized by taking positions in companies that will do better in the future through restructuring and other means. Therefore, an increase in credit spread sends a signal that these companies might have an inability to make timely interest payments. Therefore, the relationship between credit spread and Distressed returns is negative in all states of the market factor.

Distressed funds also hold bonds; therefore, the exposure to Lehman Government Credit bonds is positive in all states in the world, the highest being in the up-market (0.52).

Event Driven Multi-Strategy

Similar to previous results, the exposure to the change in VIX is positive and significant, especially during up-market periods (0.22). The strategy has a high negative exposure to credit spread in all states of the market (however, significant only for the down market). Generally, event driven types of strategies do well when credit risk premium is moderate and is declining. However, unlike Distressed strategy managers, managers in this strategy might bet on a merger or engage in other strategies during market upturns. The exposure to MSCIEMS and UMD is positive and significant only in down-market environments.

Risk Arbitrage

As for Equity Market Neutral, the linear exposure of risk factor of this strategy is limited. Below, we will investigate if non-linear exposure to other risk factors is relevant for this strategy.

As a robustness check, we check whether statistically significant coefficients are also statistically different. We investigate this aspect for different hedge fund indexes and indeed for some coefficients we cannot reject the hypothesis that they are equal. Nevertheless, even if some of the estimated coefficients are similar, we are able to find that some of them are statistically equal only in two of the three states. This confirms that factor exposure changes conditional on different states.

In summary, our results show that factor exposures are different for various factors conditional on the state of the market risk factor and for the different hedge fund indexes. A model that accounts for different factors conditional on the state of the market is richer and captures more exposures compared to previous models. Moreover, the model is showing that factor exposure is changing conditional on the state of the market. This confirms our initial hypothesis that the exposures to different risk factors are time-varying and conditional on the state of the market risk factor. Indeed, for many factors we observe that the risk exposure is zero or positive, and suddenly becomes negative or opposite during crises periods. 


\section{Omitted Factors}

The step-wise linear approach was used to limit the final list of factors for the analysis in the multifactor models with linear and non-linear exposures (Tables 5 and 6). However, the stepwise linear analysis uses linear models and might miss several risk factors that can impact the return profile of hedge fund strategies. Specifically, the step-wise linear analysis could miss phase-locking exposures, i.e., exposures that are only present during market downturns, exposures related to liquidity events and low-probability events or exposures with different signs for different regimes. In this section we attempt to account for the omitted factors and perform several analyses of potential non-linear risk exposures not highlighted in previous sections. Specifically, we are considering factors that were originally eliminated by the stepwise linear procedure and are not considered in Tables 5 and 6 .

Our analysis shows that one omitted factor for Convertible Bond Arbitrage, Dedicated Shortseller, Distressed and Risk Arbitrage strategies is the change in VIX. For these strategies VIX is important as return process of these strategies is related to market volatility. For example, convertible bonds contain imbedded equity call options that allow investors to convert the bonds into shares if share prices rise.

\section{[INSERT Table (7) about here]}

Change in VIX is a variable that needs to be interpreted jointly with different regimes of the S\&P 500 because changes in the S\&P 500 are captured by time-varying betas on the S\&P 500 (i.e., market risk exposures). For the Convertible Bond Arbitrage strategy, the effect of Change in VIX is negative in crises markets (-0.08) and positive in up-markets (0.05). The relationship between Convertible bond price and Stock price is concave when stock price is low (down-market) and highly convex when the stock price is high (up-market). Therefore, in the up-market, we will expect change in volatility to attribute to additional returns of the strategy, and in down-markets, the change in volatility negatively affects the returns of the strategy.

For Risk Arbitrage, the exposure to change in VIX is positive and significant, especially during normal periods (0.13), but negative during down-market periods (-0.09). Risk Arbitrage strategy is concerned with the success of a merger and increase in volatility in downtimes often signals an increase in probability of failure. The same applies to Distressed strategies. 
Another example is the effect of change in VIX for the Dedicated Short Bias strategy. We find that the exposure to the change in VIX is highly positive only in the negative market state (0.27), but negative in all other states (-0.42 for up-state and -0.27 for normal state). In this case the exposure to the change in VIX is opposite to the Distressed strategy potentially due to the negative market exposure of this strategy. In most of these cases the exposure to the change in VIX shows phase-locking characteristics or switch in the sign of the exposure; and this is the main reason of why linear factors are not able to capture this exposure.

Another example is the introduction of MSCIEmD for Emerging Markets strategy. We find that the exposure to this factor is negative (-0.53) during market downturn and positive during up-market (2.26) and normal conditions (0.37). For Equity market neutral we do find that this strategy is largely exposed to Term spread (1.0 in down-turn and -0.54 in the normal regime) and to Credit spread in market downturn (-1.94).

Credit spread and Term Spread were irrelevant factors for Equity Market Neutral strategy and were not considered in the models (Tables 5 and 6). We conducted an additional analysis and considered these factors. We find that in normal conditions, credit spread is irrelevant for Equity Market Neutral strategy. However, in down turns of the market, it is highly negative and significant (-1.93, t-stat: -3.15$)$. Regarding Term spread we observed a change in the sign: 1.0 in down-turn and -0.54 in the normal regime.

In conclusion, we find that using linear models and step-wise linear approach of narrowing down significant factors misses several factors for hedge fund analysis. On average, the effect of each of the factors is negligible; however, this is due to lumping the effect of each factor in up-market, down-market and normal state. We find that often an effect of a factor can be positive in an up-state, negative in a down-state and somewhere in-between for a normal

state. However, if we do not separate the factor effects into different market regimes, we underestimate the real hedge fund exposure to this factor. Moreover, we find that exposures to several factors, such as Large-Small, Credit Spread, MSCIEMD are highly negative for most of strategies in the down-market state. We argue that this exposure could be related to liquidity risk, but a deep analysis of this issue is needed and is left to further investigation.

\section{Idiosyncratic Risk Factor}

In addition to the derivation of the expected market exposures, the switching regime beta model is able to show the evolution of idiosyncratic risk of hedge funds. In particular our estimation of the Markov chain for the idiosyncratic risk of the hedge funds shows that the idiosyncratic risk is characterized by two different regimes with high and low volatility for 
6 of the 8 strategies. Exceptions are Distressed and Dedicated Shortseller that are always characterized by a large volatility regime (idiosyncratic volatility is $2.29 \%$ for Distressed and $1.34 \%$ for Dedicated Shortseller. These monthly volatilities are in-line with high volatility regimes for other strategies). The volatility parameters in the two volatility regimes (high and low) are largely different and the idiosyncratic risk factor of all 6 strategies shows that the volatility in the high regime is three or four times larger than in the low volatility regime of the idiosyncratic risk (see in Table $6 \varpi_{0}$ and $\varpi_{1}$.) The estimated probability of switching from one regime to another is on average about $10 \%$, but the probability of remaining in the same regime is about $90 \%$, meaning that regimes are quite persistent.

The estimations of the coefficients and the evolution of the probability of being in the high volatility regime for the idiosyncratic risk factor are similar across three models described in equations 2,13 and 17 . Therefore, we only depict results for the model described in equation 17 .

Referring to the model estimation presented in Table 6, in Figure 6 we show the evolution of the probability of being in the high volatility regime for all 6 strategies.

\section{[INSERT Figure(6) about here]}

Figure 6 plots monthly probabilities from January 1994 to March 2005 of hedge fund indexes facing a high volatility regime for the idiosyncratic factor, i.e. volatility of the hedge fund not related to the volatility of the S\&P 500 index and the other risk factors. We see that the evolution of the volatility of different strategies is quite different. In particular, we observe that Long/Short Equity and Emerging Market indexes present a low probability of being in the high volatility regime in the last part of the sample and a high probability in the middle of the sample that corresponds to the series of crises and rallies from 1997 till 2001. Therefore, the risk faced by the S\&P 500 already captured by the switching beta is amplified in the middle of the sample for this strategy. This indicates that not only the link with the S\&P 500 is changing, but that the idiosyncratic risk of the hedge fund index may switch to the high volatility regime at the same time when the market is characterized by turbulence. This can be explained by omitted or latent variables such as idiosyncratic liquidity risk or factors that affect mostly the hedge fund industry (as in the case of LTCM default). For example, Emerging Markets, Event Driven Multi-strategy, Long/Short Equity and Risk Arbitrage are all related to different liquidity events more or less related to the LTCM crisis. 
Event Driven Multi-Strategy almost always is characterized by the low volatility regime for its idiosyncratic risk factor; however, the probability of a high volatility regime greatly increases for periods characterized by high illiquidity events and other unexpected shocks not correlated with market returns. For example, in February 1994, the U.S. Federal Reserve started a tightening cycle that caught many hedge funds by surprise, causing significant dislocation in bond markets worldwide; the end of 1994 witnessed the start of the "Tequila Crisis" in Mexico; in August 1998, Russia defaulted on its government debt leading to a liquidity crunch in worldwide financial markets; the first quarter of 2000 saw a crash of the Internet boom, and in middle of 2002 there was a drying out of merger activities, decrease in defaults and release of news about WorldCom accounting problems. During all of these periods, the probability of a high volatility regime skyrocketed, reaching 1 for the LTCM and Russian default down-market.

The most interesting indicator is the evolution of being in the high volatility regime by the Convertible Bond Arbitrage index that indicates that it has moved to a large volatility regime from the end of 2003 and is still characterized by this regime at the end of the sample. If we consider jointly the state of the market index (normal time in the last two years) and the state of the idiosyncratic factor for the Convertible Bond Arbitrage index, we see that the switching regime beta model is able to disentangle whether the source of risk is characterized by market conditions or by potential distress in the hedge fund index strategy. Not surprisingly, April of 2005 (not in the sample period) has seen extremely low returns and high liquidations in the Convertible Bond Arbitrage sector. Just tracking market exposure will not lead to this predictive result.

We further explore the probability that all hedge fund strategies exhibit idiosyncratic risk in a high volatility regime. This could be interpreted as a proxy measure for contagion between different hedge fund strategies. Specifically, we calculate the joint probability of being in a high volatility state for all hedge funds and plot them in Figure 7 . We find that the joint probability jumps from approximately 0\% in May, 1998 to 4\% in June, 1998 to $13 \%$ in July, 1998 to $96 \%$ in August of 1998. It started to subside in October, 1998. The peak in the joint probability coincides with the liquidity crisis precipitated by the collapse of $\mathrm{LTCM}^{8}$. The results suggest that the LTCM crisis not only affected market risk factors, but also, after controlling for market and other factor exposures, it affected idiosyncratic volatility of hedge funds. This provides an evidence that even after accounting for market and other factor exposures, the LTCM crisis precipitated contagion across all hedge fund industry. In our data, we found that this was the only case where the joint probability of

\footnotetext{
${ }^{8}$ We check this result against a possibility that randomly we can have all eight strategies exhibiting high volatility regimes at the same time.
} 
being in a high volatility state for all hedge funds spiked and approached one. This result is consistent with the one provided by Boyson, Stahel and Stulz (2006) where by using extreme events, they found evidence for contagion among different hedge fund styles.

[INSERT Figure(7) about here]

\section{Robustness Analysis}

\subsection{Comparison with OLS Regression}

In a multifactor setting, we considered the model presented in equation (15) and the results for this model are contained in Table 5. The natural way to test the regime-switching model is to compare its results to results obtained using OLS regression. The results for the OLS regression are presented in Table 8 . Results are consistent, meaning, that factor loadings have the same sign in both models; however, regime-switching model is clearly superior based on pseudo- $R^{2}$ metric. For each hedge fund index, pseudo- $R^{2}$ is larger for regime-switching models compared to OLS models. Moreover, several estimates that are significant in the regime-switching model are not significant for the OLS model.

[INSERT Table (8) about here]

\subsection{Asymmetric Beta and Threshold models}

An alternative way to study time-varying non-linear hedge fund exposure to market factors is through an asymmetric beta model. In this model, the distribution of $R_{t}$ is truncated either at the median or zero and betas for "up or down" markets are compared. This approach has been applied to hedge funds in Agarwal and Naik (2004), Mitchell and Pulvino (2001), Asness, Krail and Liew (2004) and Chan, Getmansky, Haas and Lo (2005). The authors 
found significant differences between "up" and "down" betas. Specifically, they found EventDriven types of strategies including Risk Arbitrage, Distressed and Event-Driven MultiStrategy exhibit zero correlation with up-market conditions, but a large positive correlation during down-market conditions. Emerging Markets strategy shows a much higher downmarket correlation compared to up-market. Moreover, authors find that Equity-Market Neutral strategy has a much higher up-market beta compared to the down-market beta. We replicate the results and find identical results in our analysis ${ }^{9}$.

We further extend the asymmetric beta model and develop a threshold model allowing for three states. Specifically, we look at asymmetric betas in hedge fund exposure by specifying different beta coefficients for down-markets, normal markets and up-markets. Specifically, consider the following regression:

$$
R_{i t}=\alpha_{i}+\beta_{i}^{+} I_{t}^{+}+\beta_{i}^{0} I_{t}^{0}+\beta_{i}^{-} I_{t}^{-}+\epsilon_{i t}
$$

where

$I_{t}^{+}=\left\{\begin{array}{ll}I_{t} & \text { if } I_{t}>\mu+\sigma \\ 0 & \text { otherwise }\end{array} \quad I_{t}^{0}=\left\{\begin{array}{ll}I_{t} & \text { if } \mu-\sigma<I_{t}<\mu+\sigma \\ 0 & \text { otherwise }\end{array} \quad I_{t}^{-}= \begin{cases}I_{t} & \text { if } I_{t} \leq \mu+\sigma \\ 0 & \text { otherwise }\end{cases}\right.\right.$

where $I_{t}$ is the return on the index, $\mu$ is the mean and $\sigma$ is its standard deviation.

Since $I_{t}=I_{t}^{+}+I_{t}^{0}+I_{t}^{-}$, the standard linear model in which fund $i$ 's market betas are identical in up and down markets is a special case of the more general specification (20), the case where $\beta_{i}^{+}=\beta_{i}^{0}=\beta_{i}^{-}$. The specification (20) essentially tries to capture asymmetries in the index exposures.

Note the difference between the specification of this model and a regime switching model where in the latter one the expected returns and volatilities for each state are endogenously defined from the data. Also, the regime switching model may include positive returns for the down-market state and negative returns for the up-market state.

Using the specification (20), we regress hedge fund returns on the S\&P 500 index during up $\left(I_{t}^{+}\right)$, normal $\left(I_{t}^{0}\right)$ and down $\left(I_{t}^{-}\right)$conditions. The results are reported in Table 9 . Beta asymmetries are quite pronounced especially for Emerging Markets, Distressed, Event Driven Multi-Strategy and Risk Arbitrage. For example, the Distressed index has an up-market beta of 0.07 (not significant) - seemingly market neutral-however, its down-market beta is 0.38 !

\footnotetext{
${ }^{9}$ Results are not presented here, but available upon request.
} 
The exposure of the Convertible Bond Arbitrage strategy to the S\&P 500 is negligible for both up and down markets; therefore, a more comprehensive model is needed to measure the exposure of this style.

[INSERT Table (9) about here]

The results using the threshold model are similar to the ones obtained using regimeswitching methodology presented in Table 3. However, there are several numerical differ-

ences. For example, switching-regime methodology finds that Market-Neutral strategy has market-neutral exposure in all states except an up-market state. However, the threshold methodology find positive market exposure in up $\left(I_{t}^{+}\right)$and down $\left(I_{t}^{-}\right)$states. Regimeswitching methodology also identifies a positive market exposure in the "up-market" state for Emerging Market strategy; whereas, the threshold methodology misses this link.

Comparing (Table 9 and Table 5), we observe that regime-switching model fits data much better than the threshold or asymmetric beta models. For example, for all styles, pseudo$R^{2}$ for regime-switching models exceeds pseudo- $R^{2}$ for threshold models, and in particular improves model fit for Convertible Bond Arbitrage, Equity Market Neutral and Event-Driven Multi-Strategy. Therefore, the regime-switching models are able to capture linkages between hedge fund returns and the S\&P 500 that are not possible to analyze by simply splitting past returns in different return quintiles. Moreover, asymmetric and threshold models have exogenous definitions of a state. On the other hand, regime-switching methodology allows for a flexible endogenous definition of a state and is able to categorize state distributions in terms of means and variances. This cannot been done with either asymmetric or threshold models. Based on this evidence, we conclude that regime-switching methodology is superior to threshold and asymmetric models for our analysis.

\subsection{Data Smoothing Effect}

As shown by Getmansky et al. (2004) performance smoothing and illiquidity bias observed hedge fund returns and lead to autocorrelation of hedge fund returns on monthly basis. Following Getmansky et al. (2004) approach, we de-smooth returns using the following procedure: 
Denote by $R_{t}$ the true economic return of a hedge fund in period $t$, and let $R_{t}$ satisfy the following single linear factor model:

$$
\begin{aligned}
R_{t} & =\mu+\beta \Lambda_{t}+\epsilon_{t}, \quad \mathrm{E}\left[\Lambda_{t}\right]=\mathrm{E}\left[\epsilon_{t}\right]=0, \epsilon_{t}, \Lambda_{t} \sim \mathrm{IID} \\
\operatorname{Var}\left[R_{t}\right] & \equiv \sigma^{2} .
\end{aligned}
$$

True returns represent the flow of information that would determine the equilibrium value of the fund's securities in a frictionless market. However, true economic returns are not observed. Instead, $R_{t}^{o}$ denotes the reported or observed return in period $t$, and let

$$
\begin{aligned}
R_{t}^{o} & =\theta_{0} R_{t}+\theta_{1} R_{t-1}+\cdots+\theta_{k} R_{t-k} \\
\theta_{j} & \in[0,1], j=0, \ldots, k \\
1 & =\theta_{0}+\theta_{1}+\cdots+\theta_{k}
\end{aligned}
$$

which is a weighted average of the fund's true returns over the most recent $k+1$ periods, including the current period. Similar to the Getmansky et al. (2004) model, we estimate MA(2) model where $\mathrm{k}=2$ using maximum likelihood method.

\section{[INSERT Table (10) about here]}

In line with this approach we determine $R_{t}^{o}$, i.e. the "real returns" and estimate our models on the real returns. The results in Table 10 show that indeed there is evidence of data smoothing but the estimated exposure to the different factors conditional on the states of the market are largely not affected by the smoothing phenomenon. ${ }^{10}$

\subsection{Single Hedge Funds Exposure}

We investigate if the exposure we observe on hedge fund indexes are in line with those we may find for single hedge funds in order to determine the degree of heterogeneity of hedge

\footnotetext{
${ }^{10}$ We also estimate the following model for real returns and compare the estimates using the observed returns: $R_{t}=\alpha\left(Z_{t}\right)+\beta\left(S_{t}\right) I_{t}+\sum_{k=1}^{K} \theta_{k} F_{k t}+\omega\left(Z_{t}\right) u_{t}, I_{t}=\mu\left(S_{t}\right)+\sigma\left(S_{t}\right) \epsilon_{t}$. We also show that there is indeed an evidence of data smoothing; however, the estimated exposure to different factors is largely not affected by smoothing. Results are available on request.
} 
funds within each index and its effect on factor exposures. We randomly selected different hedge funds for all categories and repeated all analyses described in the paper. Results show that exposure of single hedge funds to various factors is in line with index exposures. ${ }^{11}$

\subsection{Normality of Residuals Test}

One of the reasons for introducing regime-switching approach is to address non-normality in observed hedge fund index returns. If regime-switching approach accurately describes return process of hedge fund indexes, then we will expect residuals in the regime-switching models to be normally distributed. Therefore, we implement Jarque-Bera test, which is a goodness-of-fit measure of departure from normality, based on the sample kurtosis and skewness $^{12}$.

[INSERT Table (11) about here]

Table 11 presents results for the Jarque-Bera normality tests. In the original data, normality test was rejected for all strategies except Market Neutral strategy ${ }^{13}$. The residuals in the OLS regression are normally distributed for three strategies. We then apply regimeswitching methodology. We apply two models: a multifactor model with non-linear exposure only to the S\&P 500 factor presented in equation (15) for which results are contained in Table 5 and a multifactor model with non-linear exposure to all factors presented in equation (17) for which results are presented in Table 6 . We observe that for 5 of hedge fund indexes normality test is rejected for a linear model like OLS. There is an improvement using the regime-switching model based only on the S\&P 500 factor loading (normality test is rejected for 4 out of 8 strategies). Moreover, even if we observe a rejection of normality, based on p-values, there is a strong improvement in the direction of normality, i.e. JarqueBera statistic is lower than for residuals obtained from the original data in all cases. We

\footnotetext{
${ }^{11}$ Detailed results for all models and for all individual hedge funds in each category are available upon request.

${ }^{12}$ The Jarque-Bera (JB) test statistic is defined as $J B=\frac{n-k}{6}\left(S^{2}+\frac{(K-3)^{2}}{4}\right)$, where $\mathrm{S}$ is the skewness, $\mathrm{K}$ is the kurtosis, $\mathrm{n}$ is the number of observations, and $\mathrm{k}$ is the number of estimated coefficients used to create the series. The statistic has an asymptotic chi-squared distribution with two degrees of freedom and can be used to test the null hypothesis that the data are from a normal distribution.

${ }^{13}$ Market Neutral strategy is the oldest hedge fund strategy. This investment strategy is designed to exploit equity market inefficiencies and usually involves being simultaneously long and short stocks within the same country. The strategy is not designed to use options or other non-linear instruments.
} 
see a great improvement in normality of residuals for the more elaborate model which accounts for non-linearity in all factors (equation (17)). Normality is accepted for 6 out of 8 strategies. Therefore, based on the improvement in normality in our results, we showed that regime-switching models are able to capture non-linear properties of original hedge fund index series. Nevertheless, there is still space for improvement since for two hedge funds strategies normality test is still rejected.

\section{Conclusion}

In this paper we characterized the exposure of hedge fund indexes to risk factors using switching regime beta models. In line with previous literature, we show that the market risk factor represented by the S\&P500 portfolio is characterized by three regimes: the normal state, the rolling up and downturn market and that the probabilities to switch from one regime to the other are quite different and depend on the current regime. The analysis for the sample considered indicate that the likelihood of being in the normal regime is large for the first three yeas and the last two years of the sample. This approach allows us to analyze time-varying risk exposure and phase-locking phenomenon for hedge funds, and in particular, the changes in hedge fund exposure to various risk factors conditional on the different market regimes.

We have five main results. First, hedge funds exhibit significant non-linear exposure not only to the market risk factor but also to Fama and French's (1993) size and value factors, bonds, currencies, commodities, volatility, credit and term spreads. In particular, we show that exposures can be strongly different in the down-market and up-market regimes compared to normal times suggesting that risk exposures of hedge funds in the down-market regimes are quite different than those faced during normal regimes. Moreover, many risk factor exposures could be captured only with the switching regime analysis because for many factors the exposures present a phase locking characteristic where in the normal regime the exposure is zero and in market downturn it is statistically different than zero or there is a change in the sign of the exposure.

Second, we do not find a large market factor exposure in the down-market regime for hedge fund indexes or individual hedge funds, indicating that indeed there is an effort to control market exposure. However, the exposure of other risk factors like credit spread, Large-Small, term spread or VIX are found to be large and relevant.

Third, we find that the regime switching approach explains the data better than the asymmetric or the threshold beta approach largely used in the literature and it is robust 
even after controlling for the data smoothing effect.

Fourth, the extension of the regime switching model to allow for non-linearity in residuals has suggested that switching regime models are able to capture and forecast the evolution of the idiosyncratic risk factor in terms of changes from a low volatility regime to a distressed state not directly related to market risk factors. In particular, our analysis shows that the convertible bond arbitrage distress observed in the recent period is not related to a particular regime of the market index or some other systemic risk factor, but to a switch in the volatility of the idiosyncratic risk factor of this category. Our sample is not including much of the period that has characterized the distress of the Convertible Bond Arbitrage strategy, but our estimation has allowed to forecast this potential evolution of this strategy highlighting already at the beginning of 2004 that this strategy may be entering a challenging period.

Moreover, we have allowed for a possibility and found an evidence that all the hedge fund strategies exhibit idiosyncratic risk in a high volatility regime during the sample considered. We find that for almost all of the sample the joint probability of high idiosyncratic volatility for all hedge funds is approximately zero but there are three months among the 135 considered where we find that the joint probability that all hedge funds are in the high idiosyncratic volatility regime is close to 1: at the LTCM crash. This provides an evidence that even after accounting for market and other factor exposures, the LTCM crisis precipitated contagion across the hedge fund industry. This is the only crisis event that generated this results, even though the market was characterized by other crises in the sample considered.

Finally, we investigate if there is any hedge fund exposure that is similar for all the strategies at least in one regime indicating the possibility for the hedge fund industry to be affected by the same common factor. Overall hedge fund exposures are quite different among the different strategies, however in the market downturn regime six out of eight strategies are all negatively and significantly exposed to the Large-Small risk factor. This feature is important in light with the results of Acharya and Petersen (2005) that the size risk factor is well capturing liquidity risk. Moreover, considering that liquidity shocks are highly episodic and tend to be preceded by or associated with large and negative asset return shocks, whereby liquidity risk is rendered a particularly non-linear phenomenon our results indeed suggests that liquidity is a risk factor for hedge fund returns and needs further investigation. 


\begin{tabular}{|l|l|l|l|l|l|l|l|l|l|l|l|}
\hline Variable & $\mathbf{N}$ & $\beta_{\text {S\&P50 }}$ & $\begin{array}{l}\text { Ann. } \\
\text { Mean }\end{array}$ & $\begin{array}{l}\text { Ann. } \\
\text { SD }\end{array}$ & Min & Med & Max & Skew & Kurt & $\begin{array}{l}\text { Jarque } \\
\text {-Bera } \\
\text { Stat. }\end{array}$ & $\begin{array}{l}\text { p- } \\
\text { value }\end{array}$ \\
\hline $\begin{array}{l}\text { Convertible Bond } \\
\text { Arb }\end{array}$ & 135 & 0.04 & 3.24 & 4.71 & -5.29 & 0.59 & 3.04 & -1.43 & 6.63 & 119.96 & 0.00 \\
Dedicated Shortseller & 135 & -0.89 & -6.48 & 17.63 & -9.29 & -0.95 & 22.06 & 0.83 & 4.84 & 34.58 & 0.00 \\
Emerging Markets & 135 & 0.54 & 3.12 & 16.97 & -23.68 & 0.83 & 15.92 & -0.65 & 7.13 & 105.21 & 0.00 \\
Equity Market & 135 & 0.07 & 4.08 & 2.94 & -1.68 & 0.33 & 2.68 & 0.14 & 3.32 & 1.02 & 0.60 \\
$\begin{array}{l}\text { Neutral } \\
\text { Distressed }\end{array}$ & 135 & 0.24 & 7.32 & 6.69 & -13.1 & 0.79 & 3.58 & -2.88 & 20.67 & 1942.12 & 0.00 \\
$\begin{array}{l}\text { Event Driven Multi- } \\
\text { Strategy } \\
\text { Risk Arb }\end{array}$ & 135 & 0.19 & 4.68 & 6.17 & -12.17 & 0.45 & 4.15 & -2.72 & 20.51 & 1891.51 & 0.00 \\
Long/Short Equity & 135 & 0.12 & 2.16 & 4.26 & -6.8 & 0.19 & 3.19 & -1.4 & 9.95 & 315.67 & 0.00 \\
S\&P 500 & 135 & 0.41 & 6.12 & 10.50 & -12.08 & 0.43 & 12.5 & 0.19 & 6.7 & 77.64 & 0.00 \\
\hline
\end{tabular}

Table 1: Summary statistics for monthly CSFT/Tremont hedge-fund index returns from January 1994 to March 2005. All returns are in excess of a risk-free rate. 

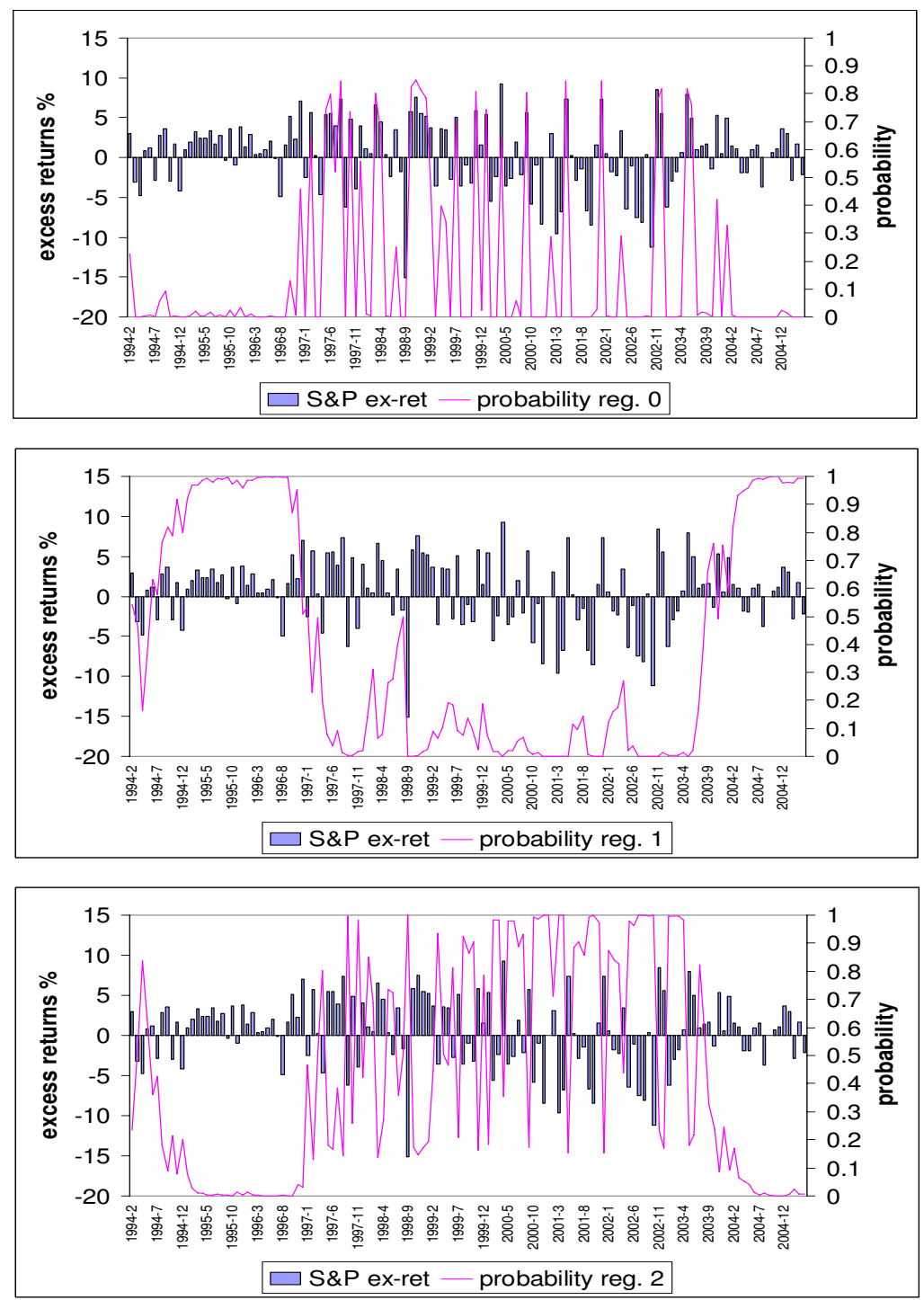

Figure 1: Market S\&P 500 excess returns and probabilities of being in a particular regime over time. There are 3 states of the market: regime 0 is an up-market regime, regime 1 is a normal regime and regime 2 is a down-market regime. 

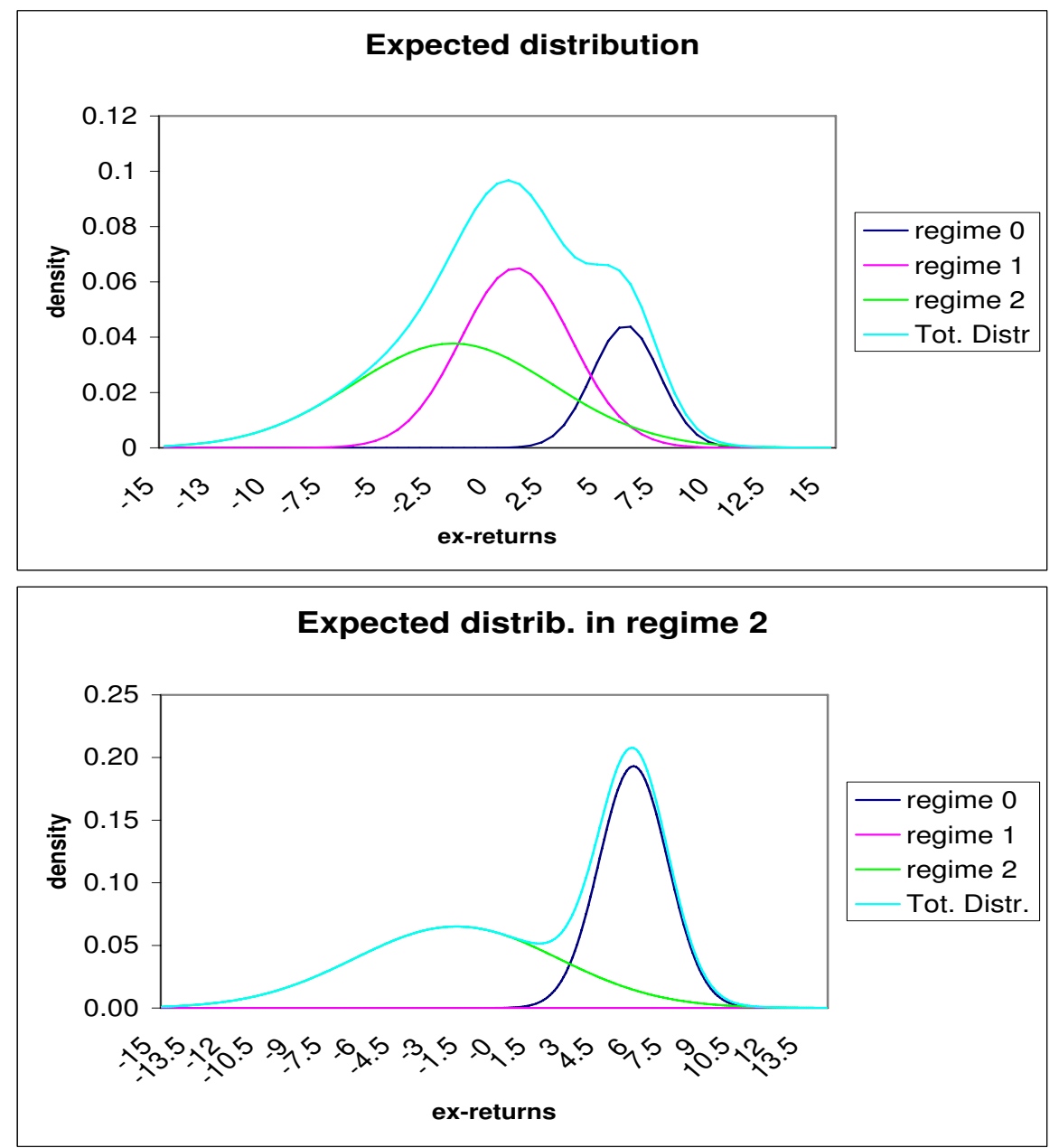

Figure 2: First figure describes unconditional distribution of S\&P 500 overall, in downmarket, up-market and normal regimes. Second figure describes conditional distribution of S\&P 500 given a down-market regime, for the overall, down-market, up-market and normal regimes. There are 3 states of the market: regime 0 is an up-market regime, regime 1 is a normal regime and regime 2 is a down-market regime. 

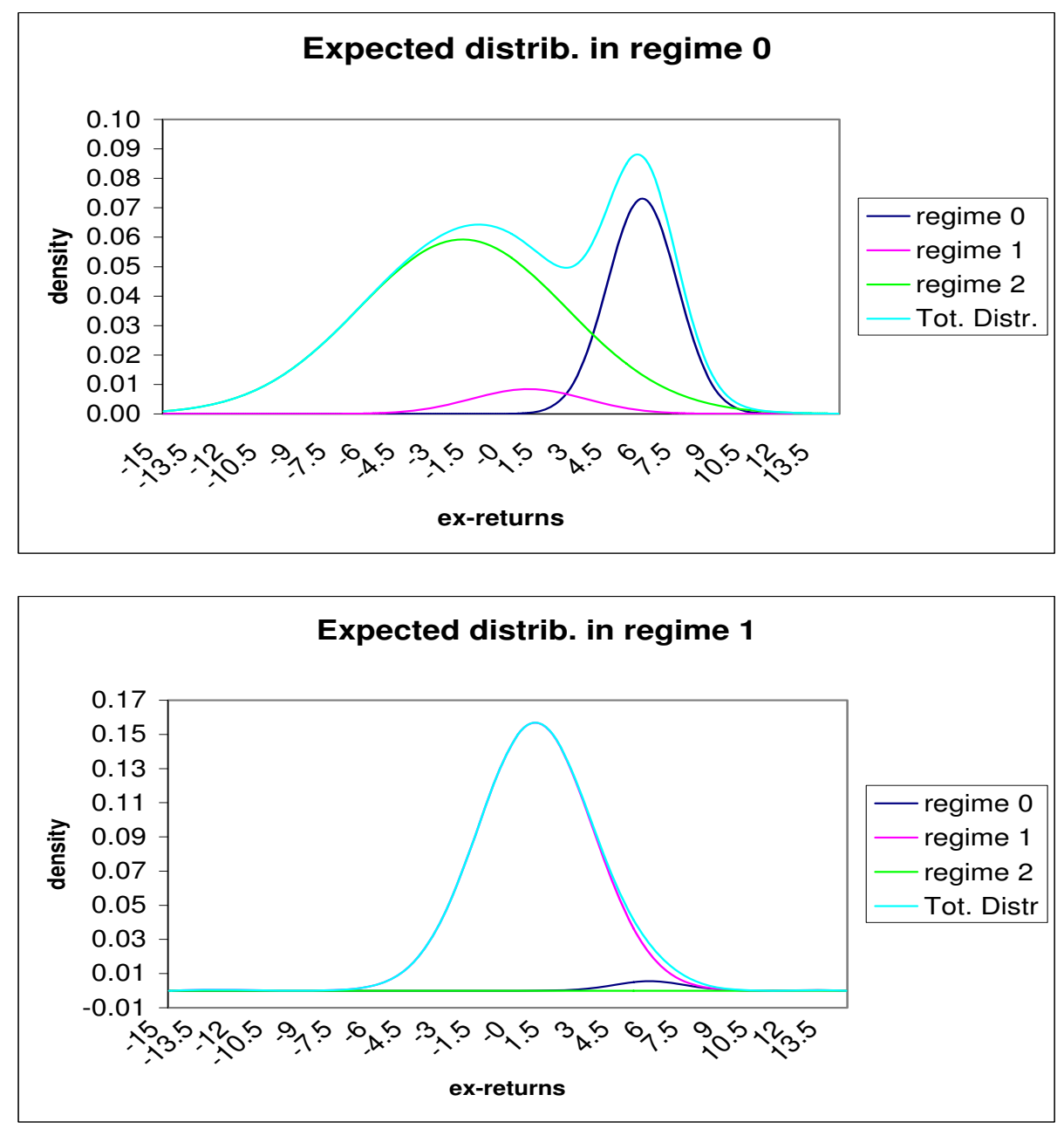

Figure 3: First figure describes conditional distribution of S\&P 500 given an up-market regime, for the overall, down-market, up-market and normal regimes. Second figure describes conditional distribution of S\&P 500 given a normal regime, for the overall, down-market, up-market and normal regimes. There are 3 states of the market: regime 0 is an up-market regime, regime 1 is a normal regime and regime 2 is a down-market regime. 


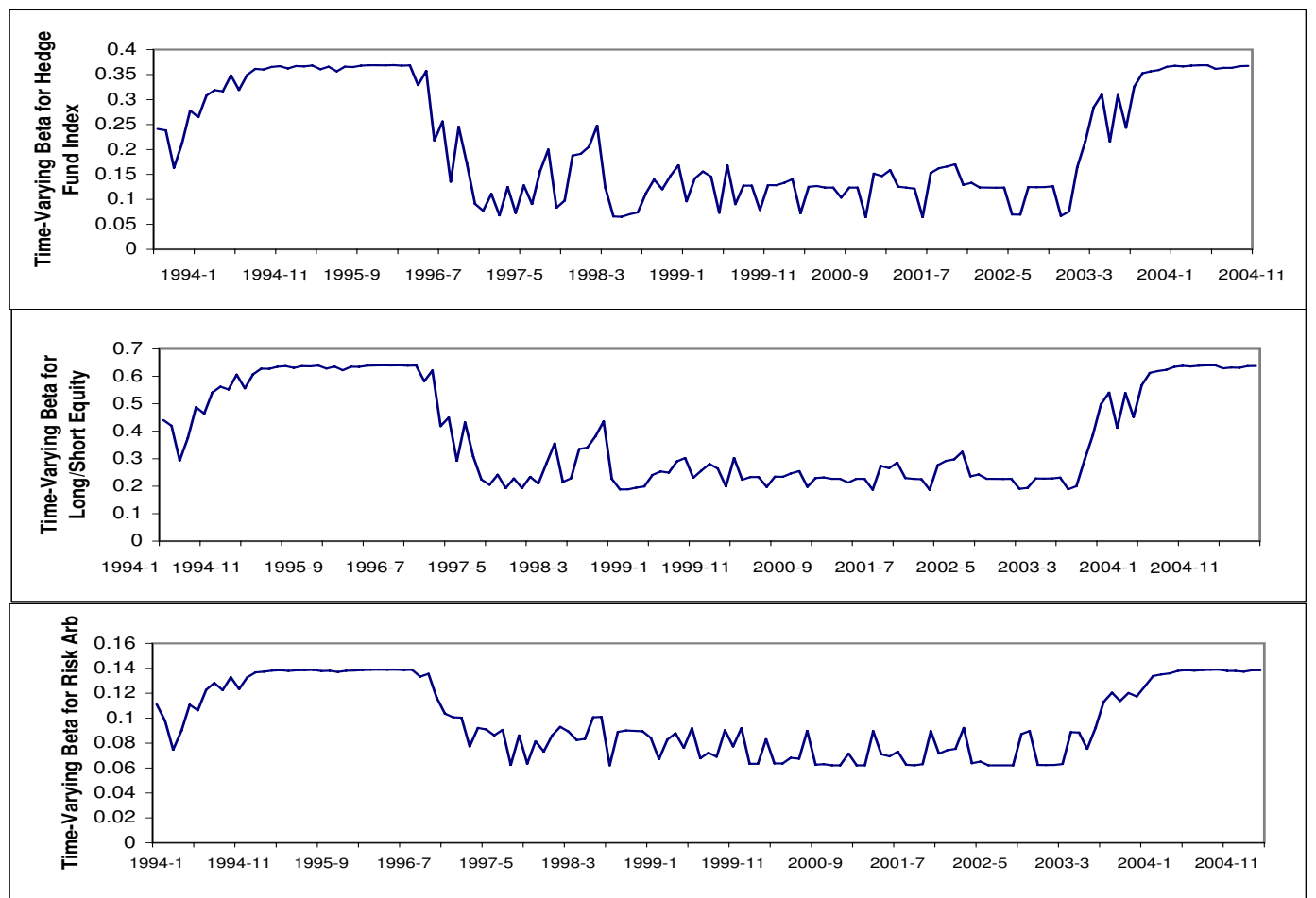

Figure 4: The evolution of market betas for Hedge fund index, Long/Short Equity and Risk Arbitrage strategies from January 1994 to March 2005. 


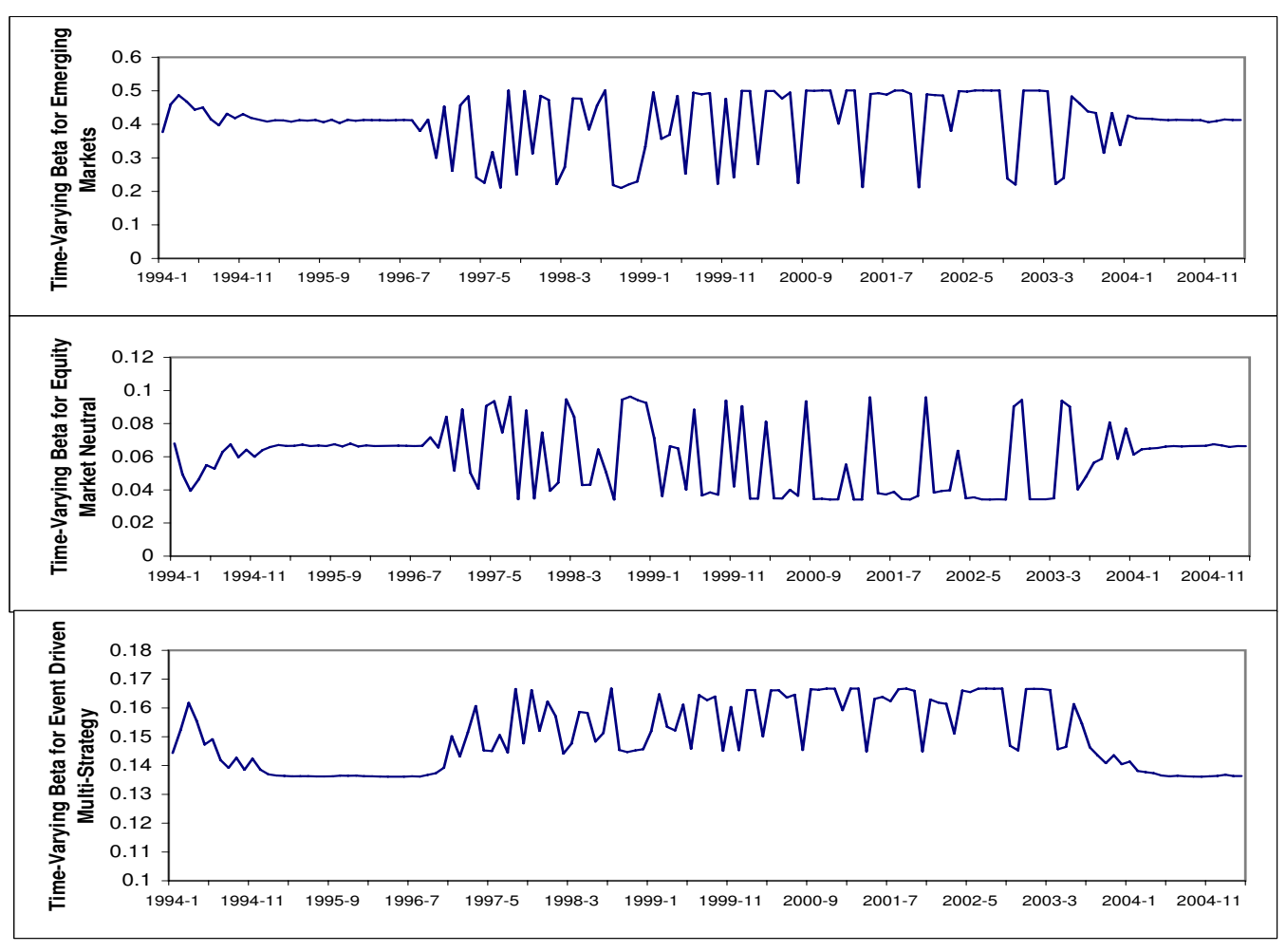

Figure 5: The evolution of market betas for Emerging Markets, Equity Market Neutral and Event Driven Multi-Strategy strategies from January 1994 to March 2005. 


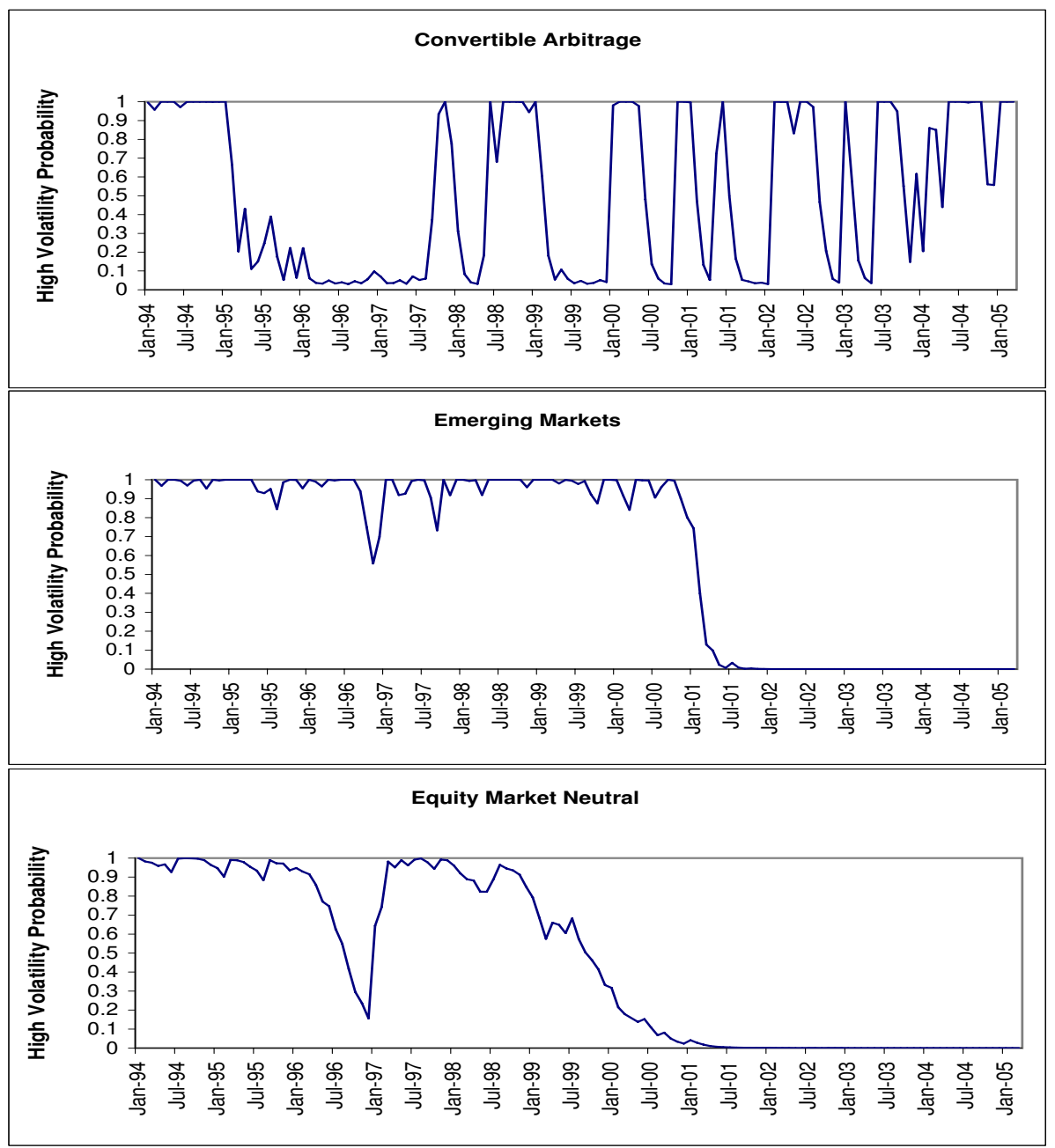

Figure 6: Part A. The evolution of the probability of being in the high volatility regime for the idiosyncratic risk factor from January 1994 to March 2005 for Convertible Bond Arbitrage, Emerging Markets and Equity Market Neutral. 


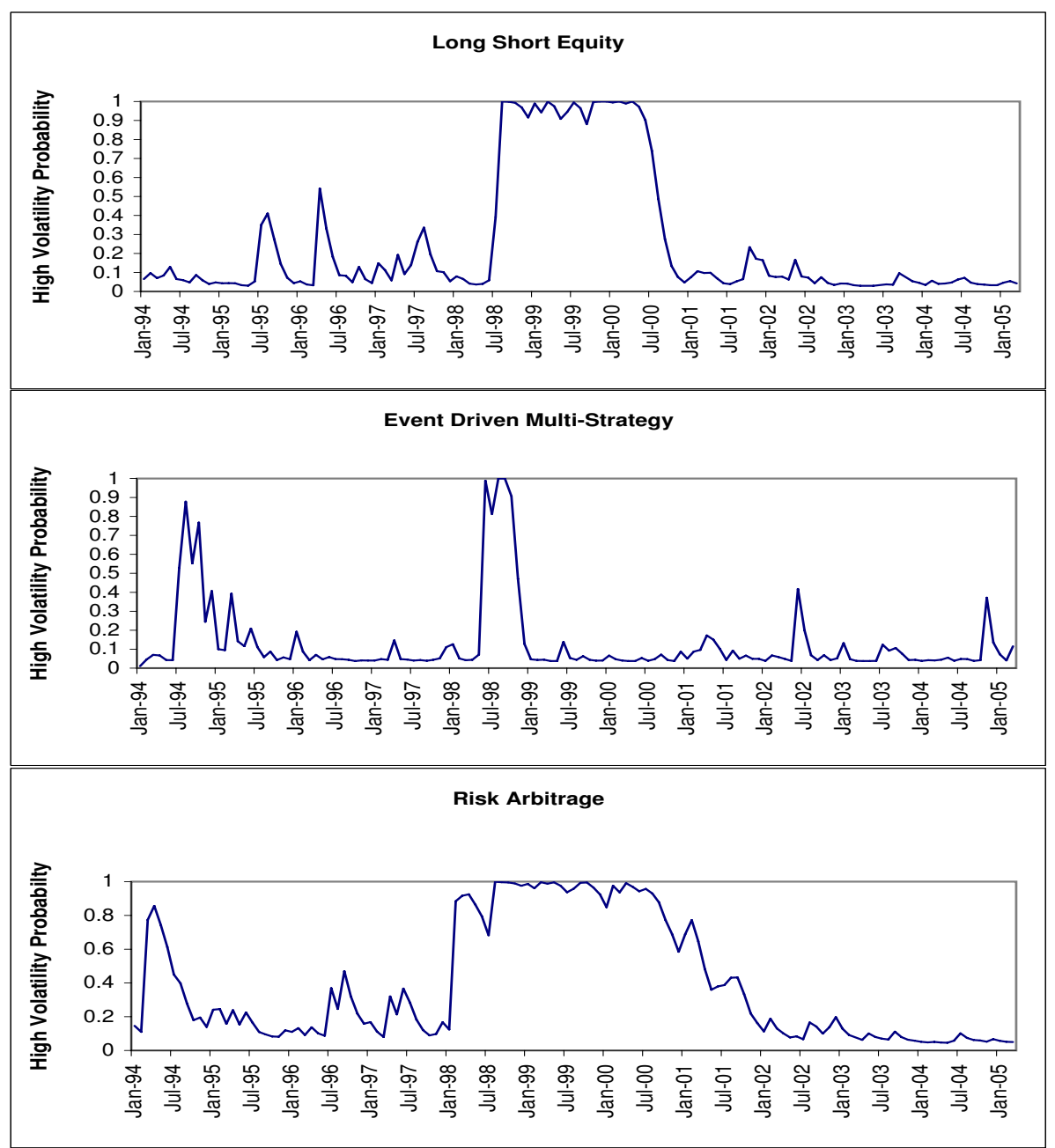

Figure 6: Part B. The evolution of the probability of being in the high volatility regime for the idiosyncratic risk factor from January 1994 to March 2005 for Long/Short Equity, Event Driven Multi-Strategy and Risk Arbitrage. 


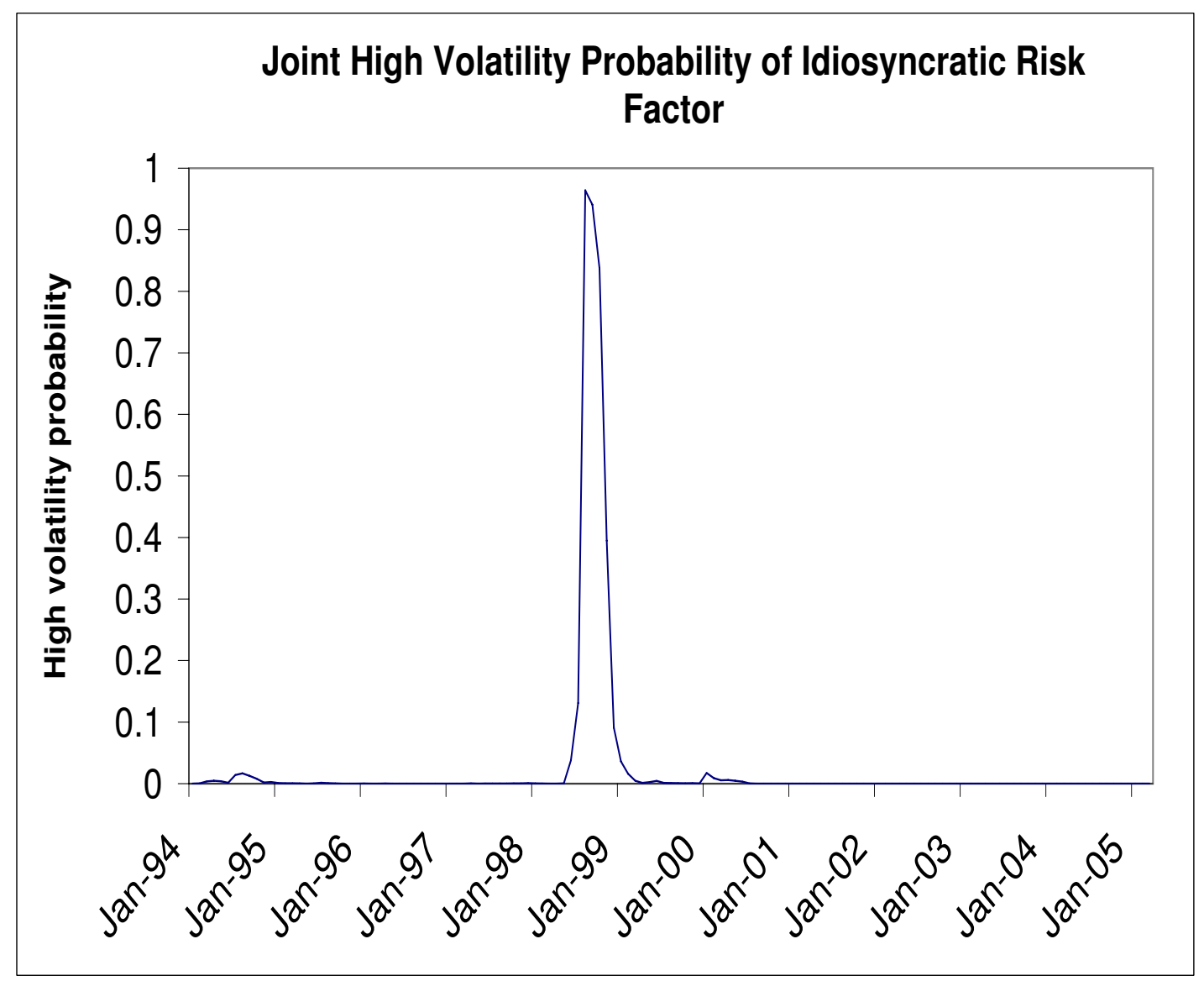

Figure 7: Probability of all hedge fund indexes being in the high volatility state of the idiosyncratic factor. Eight hedge fund strategies are considered: Convertible Bond Arbitrage, Long/Short Equity, Emerging Markets, Equity Market Neutral, Event Driven MultiStrategy, Distressed, Dedicated Shortbias and Risk Arbitrage. 


\begin{tabular}{|l|c|c|}
\hline Variable & Estimate & t-stat \\
\hline$\mu_{0}$ & $\mathbf{5 . 7 9}$ & 15.22 \\
\hline$\mu_{1}$ & $\mathbf{0 . 8 5}$ & 2.53 \\
\hline$\mu_{2}$ & $\mathbf{- 2 . 0 2}$ & -2.25 \\
\hline$\sigma_{0}$ & $\mathbf{1 . 5 2}$ & 12.80 \\
\hline$\sigma_{1}$ & $\mathbf{2 . 4 9}$ & 25.74 \\
\hline$\sigma_{2}$ & $\mathbf{4 . 5 1}$ & 29.46 \\
\hline $\mathrm{P}_{00}$ & $\mathbf{0 . 2 8}$ & 1.93 \\
\hline $\mathrm{P}_{01}$ & 0.05 & 1.17 \\
\hline $\mathrm{P}_{02}$ & $\mathbf{0 . 6 7}$ & 4.18 \\
\hline $\mathrm{P}_{10}$ & 0.02 & 0.94 \\
\hline $\mathrm{P}_{11}$ & $\mathbf{0 . 9 8}$ & 43.45 \\
\hline $\mathrm{P}_{12}$ & 0.00 & 0.00 \\
\hline $\mathrm{P}_{20}$ & $\mathbf{0 . 2 6}$ & 2.21 \\
\hline $\mathrm{P}_{21}$ & 0.00 & 0.00 \\
\hline $\mathrm{P}_{22}$ & $\mathbf{0 . 7 4}$ & 6.54 \\
\hline & & \\
\hline
\end{tabular}

Table 2: Regime switching model for the market risk factor, S\&P 500. The following model is estimated: $I_{t}=\mu\left(S_{t}\right)+\sigma\left(S_{t}\right) \epsilon_{t}$. $\mu_{i}$ and $\sigma_{i}$ are mean and standard deviation of regime i, respectively. $P_{i j}$ denotes transition probability from regime i to regime j. Parameters that are significant at the $10 \%$ level are shown in bold type. 


\begin{tabular}{|c|c|c|c|c|c|c|c|c|}
\hline \multirow{2}{*}{$\begin{array}{l}\text { Variable/ } \\
\text { Strategy }\end{array}$} & \multicolumn{2}{|c|}{ Convertible Bond Arb } & \multicolumn{2}{|c|}{ Dedicated Shortseller } & \multicolumn{2}{|c|}{ Emerging Markets } & \multicolumn{2}{|c|}{ Equity Market Neutral } \\
\hline & Estimate & t-stat & Estimate & t-stat & Estimate & t-stat & Estimate & t-stat \\
\hline$\alpha_{0}$ & 0.75 & 7.28 & 0.32 & 11.95 & 1.12 & 4.78 & 0.31 & 4.37 \\
\hline$\alpha_{1}$ & -0.57 & -2.79 & -0.13 & -0.48 & -0.09 & -0.16 & 0.16 & 1.10 \\
\hline$\beta_{0}(\mathrm{SP})$ & 0.02 & 0.84 & -0.67 & -43.38 & 0.16 & 1.56 & 0.11 & 3.42 \\
\hline$\beta_{1}(\mathrm{SP})$ & 0.06 & 1.48 & -1.26 & -61.16 & 0.41 & 2.80 & 0.07 & 1.62 \\
\hline$\beta_{2}(\mathrm{SP})$ & -0.02 & -0.92 & -0.78 & -238.32 & 0.50 & 8.57 & 0.03 & 1.50 \\
\hline$\omega_{0}$ & 0.51 & 9.17 & 0.04 & 5.77 & 1.63 & 10.50 & 0.58 & 19.90 \\
\hline$\omega_{1}$ & 1.75 & 8.93 & 3.37 & 16.60 & 5.27 & 15.21 & 0.97 & 14.82 \\
\hline $\mathrm{p}_{00}^{\mathrm{z}}$ & 0.88 & 44.04 & 0.37 & 1.86 & 0.98 & 40.56 & 0.99 & 194.28 \\
\hline $\mathrm{p}_{11}$ & 0.83 & 17.58 & 0.97 & 62.26 & 1.00 & $7.65 \mathrm{E}+06$ & 1.00 & $1.32 \mathrm{E}+06$ \\
\hline PseudoR $^{2}$ & 0.10 & & 0.12 & & 0.09 & & 0.07 & \\
\hline
\end{tabular}

\begin{tabular}{|c|c|c|c|c|c|c|c|c|}
\hline \multirow[t]{2}{*}{$\begin{array}{l}\text { Variable/ } \\
\text { Strategy }\end{array}$} & \multicolumn{2}{|c|}{ Long/Short Equity } & \multicolumn{2}{|c|}{ Distressed } & \multicolumn{2}{|c|}{$\begin{array}{c}\text { Event Driven Multi- } \\
\text { Strategy }\end{array}$} & \multicolumn{2}{|c|}{ Risk Arb } \\
\hline & Estimate & t-stat & Estimate & t-stat & Estimate & t-stat & Estimate & t-stat \\
\hline$\alpha_{0}$ & -0.10 & -0.88 & 0.68 & 6.73 & 0.52 & 6.27 & 0.21 & 2.58 \\
\hline$\alpha_{1}$ & 1.09 & 2.29 & -3.84 & -81.92 & -3.99 & -1.43 & -0.25 & -0.64 \\
\hline$\beta_{0}(\mathrm{SP})$ & 0.18 & 2.30 & 0.09 & 1.76 & 0.14 & 2.35 & 0.09 & 2.48 \\
\hline$\beta_{1}(\mathrm{SP})$ & 0.64 & 12.71 & 0.37 & 9.26 & 0.14 & 2.71 & 0.14 & 3.39 \\
\hline$\beta_{2}(\mathrm{SP})$ & 0.23 & 4.49 & 0.13 & 3.22 & 0.17 & 3.99 & 0.06 & 1.67 \\
\hline$\omega_{0}$ & 1.24 & 13.71 & 1.18 & 22.59 & 1.13 & 26.56 & 0.68 & 12.30 \\
\hline$\omega_{1}$ & 3.88 & 8.74 & 3.78 & 2.73 & 3.44 & 2.32 & 1.85 & 4.63 \\
\hline $\mathrm{p}^{\mathrm{z}}{ }_{00}$ & 0.99 & 184.05 & 0.98 & 141.58 & 0.99 & 231.66 & 0.89 & 18.36 \\
\hline $\mathrm{p}^{\mathrm{z}}{ }_{11}$ & 0.97 & 58.47 & 0.51 & 11.30 & 0.77 & 6.76 & 0.66 & 4.24 \\
\hline PseudoR $^{2}$ & 0.13 & & 0.12 & & 0.12 & & 0.08 & \\
\hline
\end{tabular}

Table 3: The exposure of CSFB/Tremont hedge-fund index strategies to different S\&P 500 regimes. The following model is estimated: $R_{t}=\alpha\left(Z_{t}\right)+\beta\left(S_{t}\right) I_{t}+\omega\left(Z_{t}\right) u_{t}, I_{t}=\mu\left(S_{t}\right)+\sigma\left(S_{t}\right) \epsilon_{t}$. Parameters that are significant at the $10 \%$ level are shown in bold type. 


\begin{tabular}{|l|ll|}
\hline Variable & Abbreviation & Definition \\
\hline S\&P500 & SP & Monthly return of the S\&P 500 index including dividends \\
Large-Small & LS & Monthly return difference between Russell 1000 and Russell 2000 indexes \\
Value-Growth & VG & Monthly return difference between Russell 1000 Value and Growth indexes \\
USD & USD & Monthly return on Bank of England Trade Weighted Index \\
Lehman Government Credit & L.GC & Monthly return of the Lehman U.S. Aggregated Government/Credit index \\
Term Spread & TS & 10-year T Bond minus 6-month LIBOR \\
Change in VIX & dVIX & Monthly change in implied volatility based on the CBOE's OEX options. \\
Credit Spread & CS & The difference between BAA and AAA indexes provide by Moody's \\
Gold & Gold & Monthly return using gold bullion \$/Troy Oz. Price \\
MSCI Emergent Bond & MSCIEmD & Monthly return of the MSCI Emergent Markets Bond Index \\
MSCI Emergent Stock & MSCIEMS & Monthly return of the MSCI Emergent Markets Stock Index \\
Momentum Factor & UMD & Momentum factor (source: Ken French website) \\
\hline
\end{tabular}

Table 4: Definitions of aggregate measures of market conditions and risk factors. All variables except Change in VIX are obtained using Datastream. Change in VIX is obtained from the CBOE. 


\begin{tabular}{|c|c|c|c|c|c|c|c|c|}
\hline \multirow{2}{*}{$\begin{array}{l}\text { Variable/ } \\
\text { Strategy }\end{array}$} & \multicolumn{2}{|c|}{ Convertible Bond Arb } & \multicolumn{2}{|c|}{ Dedicated Shortseller } & \multicolumn{2}{|c|}{ Emerging Markets } & \multicolumn{2}{|c|}{ Equity Market Neutral } \\
\hline & Estimate & t-stat & Estimate & t-stat & Estimate & t-stat & Estimate & t-stat \\
\hline$\alpha_{0}$ & 0.79 & 11.43 & 0.11 & 0.53 & 0.73 & 4.70 & 0.29 & 5.42 \\
\hline$\alpha_{1}$ & -0.38 & -2.02 & & & 0.31 & 0.95 & 0.18 & 1.25 \\
\hline$\beta_{0}(\mathrm{SP})$ & 0.04 & 1.91 & -0.87 & -9.31 & 0.24 & 2.96 & 0.11 & 3.34 \\
\hline$\beta_{1}(\mathrm{SP})$ & 0.02 & 0.42 & -1.09 & -9.97 & 0.13 & 1.49 & 0.05 & 1.04 \\
\hline$\beta_{2}(\mathrm{SP})$ & 0.01 & 0.70 & -0.77 & -5.21 & 0.39 & 5.90 & 0.03 & 1.09 \\
\hline$\theta_{1}(\mathrm{LS})$ & -0.05 & -4.21 & 0.47 & 9.91 & -0.14 & -2.57 & & \\
\hline$\theta_{2}(\mathrm{VG})$ & 0.05 & 4.79 & 0.24 & 3.52 & & & & \\
\hline$\theta_{3}$ (USD) & & & 0.32 & 2.81 & 0.27 & 4.31 & & \\
\hline$\theta_{4}($ L.GC) & 0.13 & 4.15 & & & 0.57 & 5.48 & 0.09 & 1.89 \\
\hline$\theta_{5}(\mathrm{TS})$ & & & & & 0.65 & 3.16 & & \\
\hline$\theta_{6}(\mathrm{dVIX})$ & & & & & & & & \\
\hline$\theta_{7}(\mathrm{CS})$ & -1.77 & -9.03 & -0.73 & -81.41 & & & & \\
\hline$\theta_{8}$ (Gold) & & & & & 0.08 & 2.39 & & \\
\hline$\theta_{9}(\mathrm{MSCIEMD})$ & & & 0.25 & 2.15 & & & & \\
\hline$\theta_{10}$ (MSCIEMS) & & & & & 0.21 & 6.81 & 0.02 & 1.83 \\
\hline$\theta_{11}(\mathrm{UMD})$ & & & & & 0.09 & 2.71 & & \\
\hline$\omega_{0}$ & 0.34 & 9.53 & 2.47 & 22.75 & 1.08 & 12.53 & 0.56 & 22.02 \\
\hline$\omega_{1}$ & 1.65 & 10.75 & & & 4.52 & 13.49 & 0.95 & 16.17 \\
\hline $\mathrm{p}_{00}^{\mathrm{z}}$ & 0.85 & 28.96 & & & 0.98 & 73.20 & 0.99 & 198.51 \\
\hline $\mathrm{p}^{\mathrm{z}}{ }_{11}$ & 0.85 & 26.95 & & & 1.00 & $5.06 \mathrm{E}+05$ & 1.00 & $4.65 E+05$ \\
\hline PseudoR $^{2}$ & 0.13 & & 0.18 & & 0.16 & & 0.08 & \\
\hline
\end{tabular}

Table 5: Part A. The exposure of CSFB/Tremont hedge-fund index strategies to different S\&P 500 regimes and other market factors. The following model is estimated: $R_{t}=\alpha\left(Z_{t}\right)+\beta\left(S_{t}\right) I_{t}+\sum_{k=1}^{K} \theta_{k} F_{k t}+\omega\left(Z_{t}\right) u_{t}, I_{t}=\mu\left(S_{t}\right)+\sigma\left(S_{t}\right) \epsilon_{t}$. Hedge fund returns, S\&P 500, USD, Lehman Government Credit and Gold are used in excess of LIBOR returns. Parameters that are significant at the $10 \%$ level are shown in bold type. 


\begin{tabular}{|c|c|c|c|c|c|c|c|c|}
\hline \multirow[t]{2}{*}{$\begin{array}{l}\text { Variable/ } \\
\text { Strategy }\end{array}$} & \multicolumn{2}{|c|}{ Long/Short Equity } & \multicolumn{2}{|c|}{ Distressed } & \multicolumn{2}{|c|}{$\begin{array}{c}\text { Event Driven Multi- } \\
\text { Strategy }\end{array}$} & \multicolumn{2}{|c|}{ Risk Arb } \\
\hline & Estimate & t-stat & Estimate & t-stat & Estimate & t-stat & Estimate & t-stat \\
\hline$\alpha_{0}$ & -0.16 & -1.71 & 0.73 & 5.88 & 0.53 & 5.70 & 0.06 & 0.76 \\
\hline$\alpha_{1}$ & 0.63 & 1.32 & & & -3.68 & -1.94 & 0.48 & 2.52 \\
\hline$\beta_{0}(\mathrm{SP})$ & 0.59 & 10.22 & 0.08 & 1.51 & 0.26 & 6.28 & 0.09 & 2.69 \\
\hline$\beta_{1}(\mathrm{SP})$ & 0.51 & 12.76 & 0.30 & 4.82 & 0.10 & 1.79 & 0.15 & 3.29 \\
\hline$\beta_{2}(\mathrm{SP})$ & 0.49 & 11.39 & 0.39 & 3.22 & 0.23 & 5.72 & 0.17 & 4.72 \\
\hline$\theta_{1}(\mathrm{LS})$ & -0.35 & -9.98 & -0.18 & -4.71 & -0.14 & -6.68 & -0.14 & -7.03 \\
\hline$\theta_{2}(\mathrm{VG})$ & & & 0.11 & 2.37 & 0.04 & 1.81 & 0.07 & 3.92 \\
\hline$\theta_{3}$ (USD) & & & & & 0.32 & 4.49 & & \\
\hline$\theta_{4}$ (L.GC) & 0.23 & 3.69 & 0.23 & 2.91 & & & & \\
\hline$\theta_{5}(\mathrm{TS})$ & -0.30 & -2.64 & & & & & & \\
\hline$\theta_{6}(\mathrm{dVIX})$ & 0.12 & 3.50 & & & 0.06 & 2.28 & & \\
\hline$\theta_{7}(\mathrm{CS})$ & -2.27 & -40.34 & -2.69 & -2.12 & -2.43 & -7.77 & & \\
\hline$\theta_{8}$ (Gold) & & & & & & & & \\
\hline$\theta_{9}(\mathrm{MSCIEMD})$ & & & -0.13 & -1.75 & 0.20 & 2.72 & & \\
\hline$\theta_{10}($ MSCIEMS $)$ & & & & & 0.05 & 4.10 & & \\
\hline$\theta_{11}(\mathrm{UMD})$ & 0.17 & 8.13 & & & 0.05 & 3.52 & & \\
\hline$\omega_{0}$ & 1.03 & 21.68 & 1.37 & 12.16 & 0.89 & 24.60 & 0.74 & 16.57 \\
\hline$\omega_{1}$ & 2.56 & 6.74 & & & 3.70 & 4.02 & 1.29 & 5.27 \\
\hline $\mathrm{p}_{00}^{\mathrm{z}}$ & 0.99 & 140.29 & & & 0.99 & 243.40 & 0.99 & 111.29 \\
\hline $\mathrm{p}^{\mathrm{z}}{ }_{11}$ & 0.94 & 31.39 & & & 0.72 & 4.29 & 0.96 & 32.51 \\
\hline PseudoR $^{2}$ & 0.25 & & 0.11 & & 0.20 & & 0.13 & \\
\hline
\end{tabular}

Table 5: Part B. The exposure of CSFB/Tremont hedge-fund index strategies to different S\&P 500 regimes and other market factors. The following model is estimated: $R_{t}=\alpha\left(Z_{t}\right)+\beta\left(S_{t}\right) I_{t}+\sum_{k=1}^{K} \theta_{k} F_{k t}+\omega\left(Z_{t}\right) u_{t}, I_{t}=\mu\left(S_{t}\right)+\sigma\left(S_{t}\right) \epsilon_{t}$. Hedge fund returns, S\&P 500, USD, Lehman Government Credit and Gold are used in excess of LIBOR returns. Parameters that are significant at the $10 \%$ level are shown in bold type. 


\begin{tabular}{|c|c|c|c|c|c|c|c|c|}
\hline \multirow{2}{*}{$\begin{array}{l}\text { Variable/ } \\
\text { Strategy }\end{array}$} & \multicolumn{2}{|c|}{ Convertible Bond Arb } & \multicolumn{2}{|c|}{ Dedicated Shortseller } & \multicolumn{2}{|c|}{ Emerging Markets } & \multicolumn{2}{|c|}{ Equity Market Neutral } \\
\hline & Estimate & t-stat & Estimate & t-stat & Estimate & t-stat & Estimate & t-stat \\
\hline$\alpha_{0}$ & 0.74 & 10.63 & -0.25 & -1.96 & 0.53 & 3.44 & 0.58 & 3.84 \\
\hline$\alpha_{1}$ & -0.37 & -2.01 & & & 0.41 & 0.92 & 0.05 & 0.52 \\
\hline$\beta_{0}(\mathrm{SP})$ & 0.05 & 2.08 & -0.82 & -8.62 & 0.29 & 1.75 & 0.12 & 2.74 \\
\hline$\beta_{1}(\mathrm{SP})$ & 0.05 & 0.82 & -0.91 & -9.58 & -0.13 & -1.25 & 0.08 & 2.04 \\
\hline$\beta_{2}(\mathrm{SP})$ & 0.01 & 0.63 & -0.79 & -6.80 & 0.42 & 6.30 & 0.03 & 1.40 \\
\hline$\theta_{1 \_0}(\mathrm{LS})$ & -0.02 & -0.95 & 0.24 & 2.96 & 0.04 & 0.21 & & \\
\hline$\theta_{1 \_1}(\mathrm{LS})$ & 0.00 & -0.04 & 0.92 & 10.47 & -0.19 & -1.79 & & \\
\hline$\theta_{1 \_2}(\mathrm{LS})$ & -0.09 & -4.60 & 0.43 & 5.98 & -0.21 & -2.75 & & \\
\hline$\theta_{2 \_}(\mathrm{VG})$ & 0.07 & 2.27 & -0.11 & -1.15 & & & & \\
\hline$\theta_{2 \_1}(\mathrm{VG})$ & 0.04 & 0.61 & 0.77 & 5.13 & & & & \\
\hline$\theta_{2 \_2}(\mathrm{VG})$ & 0.06 & 5.04 & 0.24 & 3.28 & & & & \\
\hline$\theta_{3 \_0}(\mathrm{USD})$ & & & 0.55 & 4.26 & 0.57 & 2.21 & & \\
\hline$\theta_{3 \_1}(\mathrm{USD})$ & & & -0.27 & -1.05 & -0.03 & -0.28 & & \\
\hline$\theta_{3 \_}(\mathrm{USD})$ & & & 0.24 & 2.56 & 0.33 & 3.82 & & \\
\hline$\theta_{4 \_0}($ L.GC $)$ & 0.18 & 2.61 & & & 1.39 & 4.51 & 0.32 & 1.51 \\
\hline$\theta_{4 \_1}($ L.GC) & 0.03 & 0.33 & & & 0.58 & 5.88 & -0.04 & -0.36 \\
\hline$\theta_{4 \_2}($ L.GC) & 0.13 & 2.49 & & & 0.47 & 2.27 & 0.07 & 0.70 \\
\hline$\theta_{5 \_0}(\mathrm{TS})$ & & & & & 0.86 & 2.58 & & \\
\hline$\theta_{5_{-1}}(\mathrm{TS})$ & & & & & 0.47 & 1.70 & & \\
\hline$\theta_{5 \_2}(\mathrm{TS})$ & & & & & 1.40 & 3.82 & & \\
\hline$\theta_{6 \_0}(\mathrm{dVIX})$ & & & & & & & & \\
\hline$\theta_{6 \_1}(\mathrm{dVIX})$ & & & & & & & & \\
\hline$\theta_{6 \_2}(\mathrm{dVIX})$ & & & & & & & & \\
\hline$\theta_{7 \_0}(\mathrm{CS})$ & -2.10 & -12.51 & 0.36 & 113.07 & & & & \\
\hline$\theta_{7 \_1}(\mathrm{CS})$ & 0.87 & 29.14 & -6.42 & -464.06 & & & & \\
\hline$\theta_{7 \_2}(\mathrm{CS})$ & -2.67 & -6.78 & 3.18 & 136.60 & & & & \\
\hline$\theta_{8 \_0}($ Gold $)$ & & & & & & & & \\
\hline$\theta_{8 \_1}($ Gold $)$ & & & & & & & & \\
\hline$\theta_{8 \_2}($ Gold $)$ & & & & & & & & \\
\hline$\theta_{9 \_0}($ MSCIEMD $)$ & & & 0.17 & 1.17 & & & & \\
\hline$\theta_{9 \_1}($ MSCIEMD) & & & -0.44 & -1.67 & & & & \\
\hline$\theta_{9 \_2}($ MSCIEMD) & & & 0.32 & 3.59 & & & & \\
\hline$\theta_{10 \_0}($ MSCIEMS $)$ & & & & & 0.44 & 4.08 & 0.04 & 1.69 \\
\hline$\theta_{10 \_1}($ MSCIEMS) & & & & & 0.32 & 6.81 & 0.00 & 0.16 \\
\hline$\theta_{10 \_2}$ (MSCIEMS) & & & & & 0.08 & 1.62 & 0.03 & 1.59 \\
\hline$\theta_{11 \_0}(\mathrm{UMD})$ & & & & & 0.17 & 1.95 & & \\
\hline$\theta_{11 \_1}(\mathrm{UMD})$ & & & & & -0.02 & -0.38 & & \\
\hline$\theta_{11 \_2}(\mathrm{UMD})$ & & & & & 0.06 & 1.35 & & \\
\hline$\omega_{0}$ & 0.31 & 6.05 & 2.29 & 20.91 & 0.94 & 11.38 & 0.47 & 3.78 \\
\hline$\omega_{1}$ & 1.65 & 9.13 & & & 4.43 & 13.66 & 0.80 & 8.35 \\
\hline $\mathrm{p}_{00}^{\mathrm{z}}$ & 0.85 & 31.29 & & & 0.98 & 102.81 & 0.93 & 27.27 \\
\hline $\mathrm{p}_{11}$ & 0.86 & 17.86 & & & 1.00 & $1.95 \mathrm{E}+05$ & 0.97 & 70.10 \\
\hline PseudoR $^{2}$ & 0.14 & & 0.2 & & 0.17 & & 0.09 & \\
\hline
\end{tabular}

Table 6: Part A. The exposure of CSFB/Tremont hedge-fund index strategies to different S\&P 500 regimes and regimes of other market factors. The following model is estimated: $R_{t}=\alpha\left(Z_{t}\right)+\beta\left(S_{t}\right) I_{t}+\sum_{k=1}^{K} \theta_{k}\left(S_{t}\right) F_{k t}+\omega\left(Z_{t}\right) u_{t}, I_{t}=\mu\left(S_{t}\right)+\sigma\left(S_{t}\right) \epsilon_{t}$. Hedge fund returns, S\&P 500, USD, Lehman Government Credit and Gold are used in excess of LIBOR returns. Parameters that are significant at the $10 \%$ level are shown in bold type. 


\begin{tabular}{|c|c|c|c|c|c|c|c|c|}
\hline \multirow[t]{2}{*}{$\begin{array}{l}\text { Variable/ } \\
\text { Strategy }\end{array}$} & \multicolumn{2}{|c|}{ Long/Short Equity } & \multicolumn{2}{|c|}{ Distressed } & \multicolumn{2}{|c|}{$\begin{array}{c}\text { Event Driven Multi- } \\
\text { Strategy }\end{array}$} & \multicolumn{2}{|c|}{ Risk Arb } \\
\hline & Estimate & t-stat & Estimate & t-stat & Estimate & t-stat & Estimate & t-stat \\
\hline$\alpha_{0}$ & -0.12 & -1.42 & 0.72 & 5.77 & 0.42 & 5.30 & 0.26 & 3.17 \\
\hline$\alpha_{1}$ & 0.68 & 8.21 & & & -3.75 & -1.26 & 0.17 & 2.02 \\
\hline$\beta_{0}(\mathrm{SP})$ & 0.73 & 8.19 & 0.11 & 1.71 & 0.35 & 7.98 & 0.06 & 3.29 \\
\hline$\beta_{1}(\mathrm{SP})$ & 0.56 & 11.87 & 0.25 & 4.25 & 0.15 & 2.55 & 0.17 & 9.23 \\
\hline$\beta_{2}(\mathrm{SP})$ & 0.38 & 9.89 & 0.40 & 2.76 & 0.13 & 3.76 & 0.20 & 20.21 \\
\hline$\theta_{100}(\mathrm{LS})$ & -0.61 & -8.01 & -0.21 & -4.69 & -0.16 & -4.76 & 0.01 & 0.72 \\
\hline$\theta_{1_{-1}}(\mathrm{LS})$ & -0.37 & -5.77 & -0.13 & -3.39 & -0.07 & -1.38 & -0.01 & -0.21 \\
\hline$\theta_{1 \_2}(\mathrm{LS})$ & -0.27 & -5.24 & -0.18 & -2.48 & -0.13 & -4.16 & -0.17 & -20.39 \\
\hline$\theta_{2 \_}(\mathrm{VG})$ & & & 0.14 & 2.07 & & & 0.12 & 7.57 \\
\hline$\theta_{2 \_1}(\mathrm{VG})$ & & & 0.02 & 0.25 & & & -0.21 & -8.98 \\
\hline$\theta_{2 \_2}(\mathrm{VG})$ & & & 0.12 & 1.46 & & & 0.10 & 7.39 \\
\hline$\theta_{3 \_}(\mathrm{USD})$ & & & & & 0.16 & 2.86 & & \\
\hline$\theta_{3-1}(\mathrm{USD})$ & & & & & 0.14 & 1.85 & & \\
\hline$\theta_{3 \_2}$ (USD) & & & & & 0.08 & 1.28 & & \\
\hline$\theta_{4 \_0}(\mathrm{~L} . \mathrm{GC})$ & 0.13 & 0.67 & 0.52 & 3.37 & & & & \\
\hline$\theta_{4-1}($ L.GC $)$ & 0.09 & 0.98 & 0.12 & 1.71 & & & & \\
\hline$\theta_{4-2}($ L.GC) & 0.34 & 2.86 & 0.23 & 3.34 & & & & \\
\hline$\theta_{5 \_0}(\mathrm{TS})$ & -0.60 & -1.75 & & & & & & \\
\hline$\theta_{5_{-1}}(\mathrm{TS})$ & -0.56 & -3.72 & & & & & & \\
\hline$\theta_{5 \_2}(\mathrm{TS})$ & 0.04 & 0.15 & & & & & & \\
\hline$\theta_{6 \_0}(\mathrm{dVIX})$ & 0.28 & 3.82 & & & 0.22 & 5.78 & & \\
\hline$\theta_{6 \_1}(\mathrm{dVIX})$ & 0.12 & 2.18 & & & 0.04 & 0.62 & & \\
\hline$\theta_{6 \_2}(\mathrm{dVIX})$ & -0.02 & -0.45 & & & -0.02 & -0.56 & & \\
\hline$\theta_{7_{-} 0}(\mathrm{CS})$ & 3.66 & 326.28 & -5.48 & -474.45 & -0.80 & -0.53 & & \\
\hline$\theta_{7_{-1}}(\mathrm{CS})$ & -1.78 & -238.74 & -3.92 & -634.87 & -2.48 & -1.13 & & \\
\hline$\theta_{7 \_2}(\mathrm{CS})$ & -3.19 & -219.43 & -1.41 & -125.03 & -1.83 & -2.47 & & \\
\hline$\theta_{8 \_0}($ Gold $)$ & & & & & & & & \\
\hline$\theta_{8 \_1}($ Gold $)$ & & & & & & & & \\
\hline$\theta_{8 \_2}($ Gold $)$ & & & & & & & & \\
\hline$\theta_{9 \_0}($ MSCIEMD $)$ & & & -0.46 & -2.94 & & & & \\
\hline$\theta_{9 \_1}($ MSCIEMD) & & & 0.05 & 1.05 & & & & \\
\hline$\theta_{9 \_2}($ MSCIEMD $)$ & & & -0.13 & -1.74 & & & & \\
\hline$\theta_{10 \_0}($ MSCIEMS $)$ & & & & & 0.02 & 0.53 & & \\
\hline$\theta_{10 \_1}($ MSCIEMS) & & & & & 0.05 & 1.38 & & \\
\hline$\theta_{10 \_2}$ (MSCIEMS) & & & & & 0.06 & 3.12 & & \\
\hline$\theta_{11 \_0}(\mathrm{UMD})$ & 0.24 & 5.26 & & & 0.03 & 1.11 & & \\
\hline$\theta_{11 \_1}(\mathrm{UMD})$ & -0.04 & -0.80 & & & -0.01 & -0.21 & & \\
\hline$\theta_{11 \_2}(\mathrm{UMD})$ & 0.16 & 5.10 & & & 0.04 & 1.95 & & \\
\hline$\omega_{0}$ & 0.90 & 19.10 & 1.34 & 8.93 & 0.88 & 18.60 & 0.06 & 3.48 \\
\hline$\omega_{1}$ & 2.43 & 7.50 & & & 3.63 & 3.15 & 1.03 & 17.94 \\
\hline $\mathrm{p}_{00}^{\mathrm{z}}$ & 0.99 & 234.44 & & & 0.99 & 137.03 & 0.36 & 1.60 \\
\hline $\mathrm{p}_{11}^{\mathrm{z}}$ & 0.94 & 27.15 & & & 0.71 & 2.42 & 0.85 & 12.48 \\
\hline PseudoR $^{2}$ & 0.28 & & 0.12 & & 0.21 & & 0.17 & \\
\hline
\end{tabular}

Table 6: Part B. The exposure of CSFB/Tremont hedge-fund index strategies to different S\&P 500 regimes and regimes of other market factors. The following model is estimated: $R_{t}=\alpha\left(Z_{t}\right)+\beta\left(S_{t}\right) I_{t}+\sum_{k=1}^{K} \theta_{k}\left(S_{t}\right) F_{k t}+\omega\left(Z_{t}\right) u_{t}, I_{t}=\mu\left(S_{t}\right)+\sigma\left(S_{t}\right) \epsilon_{t}$. Hedge fund returns, S\&P 500, USD, Lehman Government Credit and Gold are used in excess of LIBOR returns. Parameters that are significant at the $10 \%$ level are shown in bold type. 


\begin{tabular}{|c|c|c|c|c|c|c|c|c|}
\hline \multirow{2}{*}{$\begin{array}{l}\text { Variable/ } \\
\text { Strategy }\end{array}$} & \multicolumn{2}{|c|}{ Convertible Bond Arb } & \multicolumn{2}{|c|}{ Dedicated Short Bias } & \multicolumn{2}{|c|}{ Distressed } & \multicolumn{2}{|c|}{ Risk Arb } \\
\hline & Estimate & t-stat & Estimate & t-stat & Estimate & t-stat & Estimate & t-stat \\
\hline$\alpha_{0}$ & 0.77 & 11.25 & -0.16 & -0.75 & 0.63 & 6.20 & 0.02 & 0.23 \\
\hline$\alpha_{1}$ & -0.38 & -2.05 & & & & & 0.15 & 1.65 \\
\hline$\beta_{0}(\mathrm{SP})$ & 0.07 & 2.21 & -1.02 & -8.01 & 0.18 & 2.73 & 0.15 & 3.15 \\
\hline$\beta_{1}(\mathrm{SP})$ & 0.05 & 0.87 & -1.01 & -9.47 & 0.36 & 9.94 & 0.20 & 3.30 \\
\hline$\beta_{2}(\mathrm{SP})$ & -0.03 & -1.12 & -0.57 & -4.83 & 0.22 & 3.60 & 0.13 & 2.76 \\
\hline$\theta_{1 \_0}(\mathrm{LS})$ & -0.02 & -0.94 & 0.27 & 1.75 & -0.23 & -5.13 & -0.13 & -1.74 \\
\hline$\theta_{11_{1}}(\mathrm{LS})$ & 0.01 & 0.32 & 0.99 & 9.78 & -0.19 & -3.91 & -0.13 & -2.91 \\
\hline$\theta_{1 \_2}(\mathrm{LS})$ & -0.08 & -4.65 & 0.37 & 5.05 & -0.13 & -1.81 & -0.18 & -3.87 \\
\hline$\theta_{2 \_0}(\mathrm{VG})$ & 0.07 & 2.18 & -0.25 & -2.07 & 0.17 & 4.71 & 0.17 & 2.97 \\
\hline$\theta_{2 \_1}(\mathrm{VG})$ & 0.06 & 0.89 & 0.73 & 4.08 & 0.05 & 1.95 & -0.09 & -1.24 \\
\hline$\theta_{2 \_2}(\mathrm{VG})$ & 0.07 & 4.49 & 0.27 & 4.04 & 0.09 & 1.37 & 0.10 & 2.36 \\
\hline$\theta_{3 \_0}(\mathrm{USD})$ & & & 1.42 & 2.44 & & & & \\
\hline$\theta_{3 \_1}(\mathrm{USD})$ & & & -0.36 & -1.42 & & & & \\
\hline$\theta_{3 \_2}(\mathrm{USD})$ & & & 0.12 & 0.29 & & & & \\
\hline$\theta_{4 \_0}($ L.GC) & 0.14 & 1.71 & & & 0.48 & 3.12 & & \\
\hline$\theta_{4 \_1}($ L.GC) & 0.00 & -0.05 & & & 0.22 & 2.44 & & \\
\hline$\theta_{4 \_2}($ L.GC) & 0.13 & 2.81 & & & 0.23 & 2.13 & & \\
\hline$\theta_{5 \_0}(\mathrm{TS})$ & & & & & & & & \\
\hline$\theta_{5_{-1}}(\mathrm{TS})$ & & & & & & & & \\
\hline$\theta_{5_{-2}}(\mathrm{TS})$ & & & & & & & & \\
\hline$\theta_{6 \_0}(\mathrm{dVIX})$ & 0.05 & 1.79 & -0.42 & -2.69 & 0.04 & 0.53 & 0.01 & 0.26 \\
\hline$\theta_{6 \_1}(\mathrm{dVIX})$ & -0.04 & -1.20 & -0.27 & -2.22 & 0.24 & 3.33 & 0.13 & 2.42 \\
\hline$\theta_{6 \_2}(\mathrm{dVIX})$ & -0.08 & -2.98 & 0.27 & 2.15 & -0.22 & -4.06 & -0.09 & -1.66 \\
\hline$\theta_{7 \_0}(\mathrm{CS})$ & -2.02 & -12.07 & -1.97 & -0.26 & -5.22 & -97.42 & & \\
\hline$\theta_{7 \_1}(\mathrm{CS})$ & 0.40 & 4.59 & -4.96 & -8.54 & -5.71 & -106.57 & & \\
\hline$\theta_{7_{-} 2}(\mathrm{CS})$ & -2.57 & -7.06 & 3.29 & 0.92 & -1.07 & -19.99 & & \\
\hline$\theta_{8 \_0}($ Gold $)$ & & & & & & & & \\
\hline$\theta_{8 \_1}($ Gold $)$ & & & & & & & & \\
\hline$\theta_{8 \_2}($ Gold $)$ & & & & & & & & \\
\hline$\theta_{9 \_0}($ MSCIEMD $)$ & & & 1.10 & 1.75 & -0.48 & -5.34 & & \\
\hline$\theta_{9 \_1}($ MSCIEMD) & & & -0.42 & -1.53 & -0.07 & -0.71 & & \\
\hline$\theta_{9 \_2}($ MSCIEMD $)$ & & & 0.19 & 0.55 & -0.09 & -0.97 & & \\
\hline$\theta_{10 \_0}($ MSCIEMS $)$ & & & & & & & & \\
\hline$\theta_{10_{-1} 1}($ MSCIEMS $)$ & & & & & & & & \\
\hline$\theta_{10 \_2}($ MSCIEMS $)$ & & & & & & & & \\
\hline$\theta_{11 \_0}(\mathrm{UMD})$ & & & & & & & & \\
\hline$\theta_{11 \_1}(\mathrm{UMD})$ & & & & & & & & \\
\hline$\theta_{11 \_2}(\mathrm{UMD})$ & & & & & & & & \\
\hline$\omega_{0}$ & 0.31 & 5.72 & 2.22 & 21.14 & 1.29 & 10.74 & 0.36 & 6.21 \\
\hline$\omega_{1}$ & 1.61 & 10.80 & & & & & 0.94 & 14.42 \\
\hline $\mathrm{p}^{\mathrm{z}}{ }_{00}$ & 0.85 & 27.87 & & & & & 0.96 & 23.20 \\
\hline $\mathrm{p}^{\mathrm{z}}$ & 0.86 & 21.39 & & & & & 1.00 & $3.58 \mathrm{E}+05$ \\
\hline PseudoR $^{2}$ & 0.15 & & 0.21 & & 0.13 & & 0.16 & \\
\hline
\end{tabular}

Table 7: The exposure of Convertible Bond Arbitrage, Dedicated Shortseller, Distressed and Risk Arbitrage strategies to different S\&P 500 regimes and regimes of other market factors analyzed in Table 6 and the additional change in VIX factor. The following model is estimated: $R_{t}=\alpha\left(Z_{t}\right)+\beta\left(S_{t}\right) I_{t}+\sum_{k=1}^{K} \theta_{k}\left(S_{t}\right) F_{k t}+\omega\left(Z_{t}\right) u_{t}, I_{t}=\mu\left(S_{t}\right)+\sigma\left(S_{t}\right) \epsilon_{t}$. Hedge fund returns, S\&P 500, USD, Lehman Government Credit and Gold are used in excess of LIBOR returns. Parameters that are significant at the $10 \%$ level are shown in bold type. 


\begin{tabular}{|c|c|c|c|c|c|c|c|c|}
\hline \multirow{2}{*}{$\begin{array}{l}\text { Variable/ } \\
\text { Strategy }\end{array}$} & \multicolumn{2}{|c|}{ Convertible Bond Arb } & \multicolumn{2}{|c|}{ Dedicated Shortseller } & \multicolumn{2}{|c|}{ Emerging Markets } & \multicolumn{2}{|c|}{ Equity Market Neutral } \\
\hline & Estimate & t-stat & Estimate & t-stat & Estimate & t-stat & Estimate & t-stat \\
\hline$a_{0}$ & 0.23 & 2.04 & -0.10 & -0.48 & 0.32 & 3.24 & 0.31 & 4.68 \\
\hline $\mathrm{b}_{0}(\mathrm{SP})$ & 0.06 & 1.30 & -0.85 & -10.47 & 0.59 & 7.46 & 0.07 & 4.04 \\
\hline$b_{1}(L S)$ & -0.08 & -1.93 & 0.49 & 6.18 & -0.22 & -3.18 & & \\
\hline$b_{2}(\mathrm{VG})$ & 0.04 & 1.06 & 0.23 & 3.60 & & & & \\
\hline $\mathrm{b}_{3}$ (USD) & & & 0.22 & 1.05 & 0.54 & 4.89 & & \\
\hline $\mathrm{b}_{4}(\mathrm{~L} . \mathrm{GC})$ & 0.16 & 1.87 & & & 0.37 & 3.39 & 0.09 & 1.78 \\
\hline$b_{5}(\mathrm{TS})$ & & & & & 1.37 & 3.36 & & \\
\hline$b_{6}(d V I X)$ & & & & & & & & \\
\hline $\mathrm{b}_{7}(\mathrm{CS})$ & -0.97 & -0.73 & -0.31 & -40.05 & & & & \\
\hline$b_{8}$ (Gold) & & & & & 0.12 & 1.69 & & \\
\hline $\mathrm{b}_{9}$ (MSCIEMD) & & & 0.11 & 0.58 & & & & \\
\hline $\mathrm{b}_{10}$ (MSCIEMS) & & & & & 0.25 & 4.88 & 0.02 & 1.46 \\
\hline $\mathrm{b}_{11}(\mathrm{UMD})$ & & & & & 0.20 & 4.08 & & \\
\hline $\mathrm{w}_{0}$ & 1.30 & 10.20 & 2.49 & 21.27 & 3.32 & 22.03 & 0.77 & 15.42 \\
\hline Adj. $R^{2}$ & 0.04 & & 0.75 & & 0.51 & & 0.14 & \\
\hline Pseudo $\mathrm{R}^{2}$ & 0.02 & & 0.18 & & 0.10 & & 0.04 & \\
\hline
\end{tabular}

\begin{tabular}{|c|c|c|c|c|c|c|c|c|}
\hline \multirow[t]{2}{*}{$\begin{array}{l}\text { Variable/ } \\
\text { Strategy }\end{array}$} & \multicolumn{2}{|c|}{ Long/Short Equity } & \multicolumn{2}{|c|}{ Distressed } & \multicolumn{2}{|c|}{$\begin{array}{c}\text { Event Driven Multi- } \\
\text { Strategy }\end{array}$} & \multicolumn{2}{|c|}{ Risk Arb } \\
\hline & Estimate & t-stat & Estimate & t-stat & Estimate & t-stat & Estimate & t-stat \\
\hline $\mathrm{a}_{0}$ & 0.01 & 0.09 & 0.46 & 3.05 & 0.32 & 1.96 & 0.09 & 1.02 \\
\hline $\mathrm{b}_{0}(\mathrm{SP})$ & 0.57 & 12.40 & 0.29 & 4.20 & 0.23 & 4.82 & 0.17 & 4.84 \\
\hline $\mathrm{b}_{1}(\mathrm{LS})$ & -0.39 & -9.85 & -0.19 & -4.38 & -0.15 & -4.04 & -0.16 & -4.86 \\
\hline $\mathrm{b}_{2}(\mathrm{VG})$ & & & 0.11 & 2.29 & 0.10 & 2.08 & 0.08 & 3.03 \\
\hline$b_{3}$ (USD) & & & & & 0.22 & 1.78 & & \\
\hline $\mathrm{b}_{4}($ L.GC) & 0.14 & 3.19 & 0.24 & 2.54 & & & & \\
\hline $\mathrm{b}_{5}(\mathrm{TS})$ & -0.23 & -1.68 & & & & & & \\
\hline $\mathrm{b}_{6}(\mathrm{dVIX})$ & 0.09 & 1.66 & & & -0.02 & -0.37 & & \\
\hline $\mathrm{b}_{7}(\mathrm{CS})$ & -4.21 & -360.44 & -3.37 & -2.79 & -3.75 & -3.90 & & \\
\hline$b_{8}$ (Gold) & & & & & & & & \\
\hline $\mathrm{b}_{9}$ (MSCIEMD) & & & -0.15 & -2.75 & 0.03 & 0.24 & & \\
\hline $\mathrm{b}_{10}$ (MSCIEMS) & & & & & 0.06 & 2.15 & & \\
\hline $\mathrm{b}_{11}$ (UMD) & 0.23 & 7.83 & & & 0.07 & 2.77 & & \\
\hline $\mathrm{w}_{0}$ & 1.36 & 16.00 & 1.42 & 6.22 & 1.27 & 6.96 & 0.93 & 12.74 \\
\hline Adj. $\mathrm{R}^{2}$ & 0.79 & & 0.43 & & 0.46 & & 0.41 & \\
\hline Pseudo $\mathrm{R}^{2}$ & 0.23 & & 0.10 & & 0.11 & & 0.11 & \\
\hline
\end{tabular}

Table 8: The exposure of CSFB/Tremont hedge-fund index strategies to different S\&P 500 regimes. The following OLS model is estimated: $R_{t}=\alpha\left(Z_{t}\right)+\beta I_{t}+\sum_{k=1}^{K} \theta_{k} F_{k t}+\omega_{t}$. Hedge fund returns, S\&P 500, USD, Lehman Government Credit and Gold are used in excess of LIBOR returns. Parameters that are significant at the $10 \%$ level are shown in bold type. 


\begin{tabular}{|l|cc|cc|cc|cc|}
\hline $\begin{array}{l}\text { Variable/ } \\
\text { Strategy }\end{array}$ & \multicolumn{2}{l|}{$\begin{array}{l}\text { Convertible Bond Arb } \\
\end{array}$} & \multicolumn{2}{l|}{ Dedicated Shortseller } & \multicolumn{2}{|c|}{ Emerging Markets } & \multicolumn{2}{c|}{ Equity Market Neutral } \\
& Estimate & t-stat & Estimate & t-stat & Estimate & t-stat & Estimate & t-stat \\
\hline$\alpha$ & $\mathbf{0 . 3 1}$ & $\mathbf{2 . 4 0}$ & -0.29 & -0.81 & 0.45 & 1.15 & $\mathbf{0 . 2 5}$ & $\mathbf{3 . 3 7}$ \\
$\beta+$ & 0.03 & 0.39 & $\mathbf{- 0 . 8 1}$ & $\mathbf{- 8 . 8 4}$ & $\mathbf{0 . 3 4}$ & $\mathbf{3 . 0 3}$ & $\mathbf{0 . 1 3}$ & $\mathbf{4 . 4 5}$ \\
$\beta 0$ & 0.00 & -0.02 & $\mathbf{- 0 . 8 7}$ & $\mathbf{- 5 . 7 8}$ & $\mathbf{0 . 4 7}$ & $\mathbf{2 . 5 0}$ & 0.02 & 0.60 \\
$\beta-$ & 0.06 & 0.81 & $\mathbf{- 0 . 9 7}$ & $\mathbf{- 6 . 9 4}$ & $\mathbf{0 . 7 3}$ & $\mathbf{3 . 7 3}$ & $\mathbf{0 . 0 5}$ & $\mathbf{2 . 1 5}$ \\
Adj.R $^{2}$ & 0.00 & & 0.58 & & 0.23 & & 0.17 & \\
PseudoR $^{2}$ & 0.00 & & 0.11 & & 0.04 & & 0.05 & \\
\hline
\end{tabular}

\begin{tabular}{|c|c|c|c|c|c|c|c|c|}
\hline \multirow[t]{2}{*}{$\begin{array}{l}\text { Variable/ } \\
\text { Strategy }\end{array}$} & \multicolumn{2}{|c|}{ Long/Short Equity } & \multicolumn{2}{|c|}{ Distressed } & \multicolumn{2}{|c|}{$\begin{array}{c}\text { Event Driven Multi- } \\
\text { Strategy }\end{array}$} & \multicolumn{2}{|c|}{ Risk Arb } \\
\hline & Estimate & t-stat & Estimate & t-stat & Estimate & t-stat & Estimate & t-stat \\
\hline$\alpha$ & 0.36 & 1.65 & 0.84 & 5.71 & 0.55 & 3.79 & 0.24 & 2.08 \\
\hline$\beta+$ & 0.35 & 3.06 & 0.07 & 1.46 & 0.08 & 1.45 & 0.06 & 1.62 \\
\hline$\beta 0$ & 0.49 & 4.72 & 0.22 & 4.33 & 0.15 & 2.63 & 0.13 & 2.29 \\
\hline$\beta-$ & 0.42 & 4.69 & 0.38 & 2.82 & 0.30 & 2.18 & 0.17 & 2.21 \\
\hline Adj. $R^{2}$ & 0.33 & & 0.35 & & 0.25 & & 0.22 & \\
\hline PseudoR $^{2}$ & 0.06 & & 0.08 & & 0.05 & & 0.05 & \\
\hline
\end{tabular}

Table 9: Regressions of monthly CSFB/Tremont hedge-fund index returns on three regimes of the S\&P 500 index return, from January 1994 to March 2005. $R_{i t}=\alpha_{i}+\beta_{i}^{+} I_{t}^{+}+$ $\beta_{i}^{0} I_{t}^{0}+\beta_{i}^{-} I_{t}^{-}+\epsilon_{i t}$, where $I_{t}^{+}=\mu+\sigma, I_{t}^{0}=\mu-\sigma<I_{t}<\mu+\sigma, I_{t}^{-}=\mu+\sigma . I_{t}$ is the return on the index, $\mu$ is the mean and $\sigma$ is its standard deviation. Parameters that are significant at the $10 \%$ level are shown in bold type. 


\begin{tabular}{|c|c|c|c|c|c|c|c|c|}
\hline \multirow{2}{*}{$\begin{array}{l}\text { Variable/ } \\
\text { Strategy }\end{array}$} & \multicolumn{2}{|c|}{ Convertible Bond Arb } & \multicolumn{2}{|c|}{ Dedicated Shortseller } & \multicolumn{2}{|c|}{ Emerging Markets } & \multicolumn{2}{|c|}{ Equity Market Neutral } \\
\hline & Observed & Real & Observed & Real & Observed & Real & Observed & Real \\
\hline$\alpha_{0}$ & 0.74 & 0.42 & -0.25 & 1.32 & 0.53 & 0.36 & 0.58 & 0.26 \\
\hline$\alpha_{1}$ & -0.37 & 0.04 & & & 0.41 & -0.03 & 0.05 & -0.14 \\
\hline$\beta_{0}(\mathrm{SP})$ & 0.05 & 0.06 & -0.82 & 0.07 & 0.29 & 0.45 & 0.12 & 0.15 \\
\hline$\beta_{1}(\mathrm{SP})$ & 0.05 & 0.04 & -0.91 & -0.59 & -0.13 & 0.06 & 0.08 & 0.08 \\
\hline$\beta_{2}(\mathrm{SP})$ & 0.01 & 0.04 & -0.79 & -0.06 & 0.42 & 0.48 & 0.03 & 0.04 \\
\hline$\theta_{1 \_0}(\mathrm{LS})$ & -0.02 & -0.08 & 0.24 & -0.27 & 0.04 & -0.02 & & \\
\hline$\theta_{1 \_1}(\mathrm{LS})$ & 0.00 & 0.06 & 0.92 & 0.70 & -0.19 & -0.20 & & \\
\hline$\theta_{1 \_2}(\mathrm{LS})$ & -0.09 & -0.10 & 0.43 & 0.76 & -0.21 & -0.22 & & \\
\hline$\theta_{2 \_}(\mathrm{VG})$ & 0.07 & 0.10 & -0.11 & -0.55 & & & & 0.10 \\
\hline$\theta_{2 \_1}(\mathrm{VG})$ & 0.04 & 0.01 & 0.77 & 0.88 & & & & 0.03 \\
\hline$\theta_{2 \_2}(\mathrm{VG})$ & 0.06 & 0.06 & 0.24 & -0.03 & & & & -0.01 \\
\hline$\theta_{3 \_0}(\mathrm{USD})$ & & & 0.55 & -0.63 & 0.57 & 0.48 & & \\
\hline$\theta_{3-1}$ (USD) & & & -0.27 & -0.02 & -0.03 & 0.04 & & \\
\hline$\theta_{3 \_2}$ (USD) & & & 0.24 & -1.27 & 0.33 & 0.33 & & \\
\hline$\theta_{4 \_0}($ L.GC) & 0.18 & 0.13 & & & 1.39 & 0.89 & 0.32 & \\
\hline$\theta_{4-1}($ L.GC) & 0.03 & -0.02 & & & 0.58 & 0.61 & -0.04 & \\
\hline$\theta_{4 \_2}($ L.GC) & 0.13 & 0.14 & & & 0.47 & 0.75 & 0.07 & \\
\hline$\theta_{5 \_0}(\mathrm{TS})$ & & & & & 0.86 & 0.24 & & \\
\hline$\theta_{5_{-1}}(\mathrm{TS})$ & & & & & 0.47 & 0.45 & & \\
\hline$\theta_{5-2}(\mathrm{TS})$ & & & & & 1.40 & 1.50 & & \\
\hline$\theta_{6 \_0}(\mathrm{dVIX})$ & & & & & & & & \\
\hline$\theta_{6 \_1}(\mathrm{dVIX})$ & & & & & & & & \\
\hline$\theta_{6 \_2}(\mathrm{dVIX})$ & & & & & & & & \\
\hline$\theta_{7_{-} 0}(\mathrm{CS})$ & -2.10 & 0.04 & 0.36 & 14.94 & & & & \\
\hline$\theta_{7_{-1}}(\mathrm{CS})$ & 0.87 & -1.93 & -6.42 & -19.15 & & & & \\
\hline$\theta_{7_{-2}}(\mathrm{CS})$ & -2.67 & -1.98 & 3.18 & 17.79 & & & & \\
\hline$\theta_{8 \_0}($ Gold $)$ & & & & & & & & \\
\hline$\theta_{8 \_1}($ Gold $)$ & & & & & & & & \\
\hline$\theta_{8 \_2}($ Gold $)$ & & & & & & & & \\
\hline$\theta_{9 \_0}($ MSCIEMD $)$ & & & 0.17 & 0.58 & & & & \\
\hline$\theta_{9 \_1}($ MSCIEMD) & & & -0.44 & -0.43 & & & & \\
\hline$\theta_{9 \_2}($ MSCIEMD) & & & 0.32 & -1.29 & & & & \\
\hline$\theta_{10 \_0}($ MSCIEMS $)$ & & & & & 0.44 & 0.16 & 0.04 & 0.01 \\
\hline$\theta_{10 \_1}($ MSCIEMS $)$ & & & & & 0.32 & 0.24 & 0.00 & 0.00 \\
\hline$\theta_{10 \_2}($ MSCIEMS $)$ & & & & & 0.08 & -0.03 & 0.03 & 0.02 \\
\hline$\theta_{11 \_0}(\mathrm{UMD})$ & & & & & 0.17 & 0.15 & & \\
\hline$\theta_{11 \_1}(\mathrm{UMD})$ & & & & & -0.02 & 0.01 & & \\
\hline$\theta_{11 \_2}(\mathrm{UMD})$ & & & & & 0.06 & -0.01 & & \\
\hline$\omega_{0}$ & 0.31 & 0.31 & 2.29 & 5.13 & 0.94 & 1.10 & 0.47 & 0.42 \\
\hline$\omega_{1}$ & 1.65 & 1.33 & & & 4.43 & 4.33 & 0.80 & 0.80 \\
\hline $\mathrm{p}_{00}^{\mathrm{z}}$ & 0.85 & 0.84 & & & 0.98 & 0.98 & 0.93 & 0.93 \\
\hline $\mathrm{p}_{11}^{\mathrm{z}}$ & 0.86 & 0.88 & & & 1.00 & 1.00 & 0.97 & 0.98 \\
\hline PseudoR $^{2}$ & 0.14 & 0.17 & 0.20 & 0.19 & 0.17 & 0.16 & 0.09 & 0.11 \\
\hline
\end{tabular}

Table 10. Part A. The exposure of CSFB/Tremont hedge-fund index strategies to different S\&P 500 regimes and regimes of other market factors for both observed and real hedge fund index returns. The following model is estimated: $R_{t}=\alpha\left(Z_{t}\right)+\beta\left(S_{t}\right) I_{t}+\sum_{k=1}^{K} \theta_{k}\left(S_{t}\right) F_{k t}+\omega\left(Z_{t}\right) u_{t}, I_{t}=\mu\left(S_{t}\right)+\sigma\left(S_{t}\right) \epsilon_{t}$. Hedge fund returns, S\&P 500, USD, Lehman Government Credit and Gold are used in excess of LIBOR returns. Real returns are obtained by using $\mathrm{MA}(2)$ estimation via maximum likelihood. Parameters that are significant at the $10 \%$ level are shown in bold type. 


\begin{tabular}{|c|c|c|c|c|c|c|c|c|}
\hline \multirow[t]{2}{*}{$\begin{array}{l}\text { Variable/ } \\
\text { Strategy }\end{array}$} & \multicolumn{2}{|c|}{ Long/Short Equity } & \multicolumn{2}{|c|}{ Distressed } & \multicolumn{2}{|c|}{$\begin{array}{c}\text { Event Driven Multi- } \\
\text { Strategy }\end{array}$} & \multicolumn{2}{|c|}{ Risk Arb } \\
\hline & Observed & Real & Observed & Real & Observed & Real & Observed & Real \\
\hline$\alpha_{0}$ & -0.12 & -0.54 & 0.72 & 0.29 & 0.42 & -0.70 & 0.26 & 0.02 \\
\hline$\alpha_{1}$ & 0.68 & -0.04 & & & -3.75 & 0.21 & 0.17 & \\
\hline$\beta_{0}(\mathrm{SP})$ & 0.73 & 0.68 & 0.11 & 0.10 & 0.35 & 0.31 & 0.06 & 0.10 \\
\hline$\beta_{1}(\mathrm{SP})$ & 0.56 & 0.56 & 0.25 & 0.22 & 0.15 & 0.16 & 0.17 & 0.10 \\
\hline$\beta_{2}(\mathrm{SP})$ & 0.38 & 0.31 & 0.40 & 0.40 & 0.13 & 0.17 & 0.20 & 0.20 \\
\hline$\theta_{1 \_0}(\mathrm{LS})$ & -0.61 & -0.62 & -0.21 & -0.19 & -0.16 & -0.23 & 0.01 & -0.15 \\
\hline$\theta_{1_{-1}}(\mathrm{LS})$ & -0.37 & -0.37 & -0.13 & -0.12 & -0.07 & -0.07 & -0.01 & -0.05 \\
\hline$\theta_{1 \_2}(\mathrm{LS})$ & -0.27 & -0.24 & -0.18 & -0.16 & -0.13 & -0.13 & -0.17 & -0.19 \\
\hline$\theta_{2 \_0}(\mathrm{VG})$ & & -0.06 & 0.14 & 0.05 & & & 0.12 & 0.11 \\
\hline$\theta_{2 \_1}(\mathrm{VG})$ & & 0.05 & 0.02 & 0.01 & & & -0.21 & -0.13 \\
\hline$\theta_{2 \_2}(\mathrm{VG})$ & & -0.08 & 0.12 & 0.10 & & & 0.10 & 0.08 \\
\hline$\theta_{3 \_0}(\mathrm{USD})$ & & & & & 0.16 & 0.26 & & \\
\hline$\theta_{3 \_1}(\mathrm{USD})$ & & & & & 0.14 & 0.02 & & \\
\hline$\theta_{3-2}(\mathrm{USD})$ & & & & & 0.08 & 0.05 & & \\
\hline$\theta_{4 \_0}($ L.GC) & 0.13 & 0.23 & 0.52 & 0.63 & & & & \\
\hline$\theta_{4_{-} 1}(\mathrm{~L} . \mathrm{GC})$ & 0.09 & 0.07 & 0.12 & 0.10 & & & & \\
\hline$\theta_{4 \_2}($ L.GC) & 0.34 & 0.39 & 0.23 & 0.34 & & & & \\
\hline$\theta_{5 \_0}(\mathrm{TS})$ & -0.60 & -0.71 & & & & & & \\
\hline$\theta_{5-1}(\mathrm{TS})$ & -0.56 & -0.36 & & & & & & \\
\hline$\theta_{5 \_2}(\mathrm{TS})$ & 0.04 & 0.08 & & & & & & \\
\hline$\theta_{6_{-} 0}(\mathrm{dVIX})$ & 0.28 & 0.19 & & & 0.22 & 0.17 & & \\
\hline$\theta_{6_{-} 1}(\mathrm{dVIX})$ & 0.12 & 0.07 & & & 0.04 & -0.03 & & \\
\hline$\theta_{6 \_2}(\mathrm{dVIX})$ & -0.02 & -0.08 & & & -0.02 & -0.04 & & \\
\hline$\theta_{7_{-} 0}(\mathrm{CS})$ & 3.66 & & -5.48 & -3.19 & -0.80 & 0.70 & & \\
\hline$\theta_{7_{-1}}(\mathrm{CS})$ & -1.78 & & -3.92 & -2.93 & -2.48 & -2.98 & & \\
\hline$\theta_{7_{-} 2}(\mathrm{CS})$ & -3.19 & & -1.41 & -1.44 & -1.83 & -1.77 & & \\
\hline$\theta_{8 \_0}($ Gold $)$ & & & & & & & & \\
\hline$\theta_{8_{-} 1}($ Gold $)$ & & & & & & & & \\
\hline$\theta_{8 \_2}($ Gold $)$ & & & & & & & & \\
\hline$\theta_{9 \_0}(\mathrm{MSCI}$ & MD) & & -0.46 & -0.16 & & & & \\
\hline$\theta_{9 \_1}(\mathrm{MSCIF}$ & MD) & & 0.05 & 0.07 & & & & \\
\hline$\theta_{99_{-2}}(\mathrm{MSCII}$ & MD) & & -0.13 & -0.14 & & & & \\
\hline$\theta_{10 \_0}(\mathrm{MSCI}$ & EMS) & & & & 0.02 & -0.01 & & \\
\hline$\theta_{10 \_1}(\mathrm{MSCI}$ & EMS) & & & & 0.05 & 0.01 & & \\
\hline$\theta_{10 \_2}(\mathrm{MSCI}$ & EMS) & & & & 0.06 & 0.02 & & \\
\hline$\theta_{11 \_0}(\mathrm{UMD}$ & 0.24 & 0.26 & & & 0.03 & 0.01 & & \\
\hline$\theta_{11 \_1}(\mathrm{UMD}$ & -0.04 & -0.06 & & & -0.01 & 0.01 & & \\
\hline$\theta_{11 \_2}(\mathrm{UMD}$ & 0.16 & 0.17 & & & 0.04 & 0.04 & & \\
\hline$\omega_{0}$ & 0.90 & 0.85 & 1.34 & 1.24 & 0.88 & 0.79 & 0.06 & 0.86 \\
\hline$\omega_{1}$ & 2.43 & 2.17 & & & 3.63 & 2.25 & 1.03 & \\
\hline $\mathrm{p}^{\mathrm{z}}{ }_{00}$ & 0.99 & 0.99 & & & 0.99 & 0.87 & 0.36 & \\
\hline $\mathrm{p}_{11}^{\mathrm{z}}$ & 0.94 & 0.94 & & & 0.71 & 0.98 & 0.85 & \\
\hline PseudoR $^{2}$ & 0.28 & 0.27 & 0.12 & 0.15 & 0.21 & 0.21 & 0.17 & 0.16 \\
\hline
\end{tabular}

Table 10: Part B. The exposure of CSFB/Tremont hedge-fund index strategies to different S\&P 500 regimes and regimes of other market factors for both observed and real hedge fund index returns. The following model is estimated: $R_{t}=\alpha\left(Z_{t}\right)+\beta\left(S_{t}\right) I_{t}+\sum_{k=1}^{K} \theta_{k}\left(S_{t}\right) F_{k t}+\omega\left(Z_{t}\right) u_{t}, I_{t}=\mu\left(S_{t}\right)+\sigma\left(S_{t}\right) \epsilon_{t}$. Hedge fund returns, S\&P 500, USD, Lehman Government Credit and Gold are used in excess of LIBOR returns. Real returns are obtained by using $\mathrm{MA}(2)$ estimation via maximum likelihood. Parameters that are significant at the $10 \%$ level are shown in bold type. 


\begin{tabular}{|l|cc|cc|ccc|c|}
\hline \multicolumn{1}{|c|}{ Strategy/Model } & \multicolumn{2}{c}{ Original Data } & \multicolumn{2}{c|}{ OLS } & \multicolumn{2}{c|}{ Table 5 } & \multicolumn{2}{c|}{ Table 6 } \\
& JB statistic & p-value & JB statistic & p-value & JB statistic & p-value & JB statistic & p-value \\
\hline Convertible Bond Arb. & $\mathbf{1 1 9 . 9 7}$ & $\mathbf{0 . 0 0}$ & $\mathbf{6 5 . 5 4}$ & $\mathbf{0 . 0 0}$ & $\mathbf{4 8 . 1 5}$ & $\mathbf{0 . 0 0}$ & $\mathbf{4 5 . 6 4}$ & $\mathbf{0 . 0 0}$ \\
Dedicated Shortseller & $\mathbf{3 4 . 5 8}$ & $\mathbf{0 . 0 0}$ & 2.98 & 0.20 & 3.58 & 0.17 & 5.71 & 0.06 \\
Emerging Markets & $\mathbf{1 0 5 . 2 1}$ & $\mathbf{0 . 0 0}$ & $\mathbf{1 8 . 7 5}$ & $\mathbf{0 . 0 0}$ & $\mathbf{1 8 . 1 3}$ & $\mathbf{0 . 0 0}$ & 5.69 & 0.06 \\
Equity Market Neutral & 1.02 & 0.60 & 0.16 & 0.80 & 1.22 & 0.54 & 1.23 & 0.54 \\
Long/Short Equity & $\mathbf{7 7 . 6 4}$ & $\mathbf{0 . 0 0}$ & 0.14 & 0.80 & 2.11 & 0.35 & 2.38 & 0.30 \\
Distressed & $\mathbf{1 9 4 2 . 1 2}$ & $\mathbf{0 . 0 0}$ & $\mathbf{3 3 3 . 6 7}$ & $\mathbf{0 . 0 0}$ & $\mathbf{1 2 6 . 5 2}$ & $\mathbf{0 . 0 0}$ & $\mathbf{1 3 5 . 1 9}$ & $\mathbf{0 . 0 0}$ \\
Event Driven M.S. & $\mathbf{1 8 9 1 . 5 1}$ & $\mathbf{0 . 0 0}$ & $\mathbf{8 3 6 . 2 7}$ & $\mathbf{0 . 0 0}$ & 2.56 & 0.28 & 4.39 & 0.11 \\
Risk Arbitrage & $\mathbf{3 1 5 . 6 7}$ & $\mathbf{0 . 0 0}$ & $\mathbf{1 0 9 . 0 1}$ & $\mathbf{0 . 0 0}$ & $\mathbf{9 . 2 6}$ & $\mathbf{0 . 0 1}$ & 4.54 & 0.10 \\
\hline
\end{tabular}

Table 11: Jarque-Bera statistics and corresponding p-values for Centralized Normalized Hedge, Filtered Residuals and Smoothed Residuals for all hedge fund indexes. Panel A uses the following regime-switching model: $R_{t}=\alpha\left(Z_{t}\right)+\beta\left(S_{t}\right) I_{t}+\sum_{k=1}^{K} \theta_{k} F_{k t}+\omega\left(Z_{t}\right) u_{t}, I_{t}=\mu\left(S_{t}\right)+\sigma\left(S_{t}\right) \epsilon_{t}$. Panel B uses the following regime-switching model: $\quad R_{t}=\alpha\left(Z_{t}\right)+\beta\left(S_{t}\right) I_{t}+\sum_{k=1}^{K} \theta_{k}\left(S_{t}\right) F_{k t}+\omega\left(Z_{t}\right) u_{t}, I_{t}=\mu\left(S_{t}\right)+\sigma\left(S_{t}\right) \epsilon_{t}$. Jarque-Bera test statistics that lead to rejection of normality of residuals are shown in bold. For these tests, p-value is equal or smaller than 0.05 . 


\section{References}

Acharya V. and S. Schaefer, 2006, "Liquidity Risk and Correlation Risk: Implications for Risk Management", London Business School Working Paper.

Acharya V. and H. Pedersen, 2004, "Asset Pricing with Liquidity Risk", Journal of Financial Economics 77, 2, 375-410.

Ackermann, C., McEnally, R. and D. Ravenscraft, 1999, "The Performance of Hedge Funds: Risk, Return, and Incentives", Journal of Finance 54, 833-874.

Agarwal, V. and N. Naik, 2000a, "Performance Evaluation of Hedge Funds with Buy-and-Hold and Option-Based Strategies", Hedge Fund Centre Working Paper No. HF-003, London Business School.

Agarwal, V. and N. Naik, 2000b, "On Taking the 'Alternative' Route: The Risks, Rewards, and Performance Persistence of Hedge Funds", Journal of Alternative Investments 2, 6-23.

Agarwal, V. and N. Naik, 2000c, "Multi-Period Performance Persistence Analysis of Hedge Funds Source", Journal of Financial and Quantitative Analysis $35,327-342$.

Agarwal, V. and N. Naik, 2000d, "Generalized Style Analysis of Hedge Funds", Journal of Asset Management 1, 93-109.

Agarwal, V. and N. Naik, 2004, "Risks and Portfolio Decisions Involving Hedge Funds", Review of Financial Studies 17, 63-98.

Agarwal, A., Daniel, N. and N. Naik, 2004, "Flows, Performance and Managerial Incentives in Hedge Funds", Working Paper, Georgia State University.

Alexander, C., and A. Dimitriu, 2005, "Indexing, Cointegration and Equity Market Regimes", International Journal of Finance and Economics 10, $1-10$.

Allen F. and D. Gale, 1994, "Liquidity Preference, Market Participation and Asset Price Volatility", American Economic Review 84, 933-955.

Allen F. and D. Gale, 1998, "Optimal Financial Crisis", Journal of Finance 53, 1245-1284.

Ang, A. and G. Bekaert, 2002, "International Asset Allocation With Regime Shifts", The Review of Financial Studies 15, 4, 1137-1187.

Ang, A. and G. Bekaert, 2004, "How Regimes Affect Asset Allocation", Financial Analysts Journal 60, 86-99. 
Asness, C., Krail, R. and J. Liew, 2001, "Do Hedge Funds Hedge?", The Journal of Portfolio Management 28, 6-19.

Bae, K., Karolyi, G. and R. Stulz, 2003, "A New Approach to Measuring Financial Contation", The Review of Financial Studies 16, 717-763.

Bali, T., Gokcan, S. and B. Liang, 2005, "Value at Risk and the Cross-Section of Hedge Fund Returns", Journal of Banking and Finance (Forthcoming).

Bekaert, G. and C. Harvey, 1995, "Time-Varying World Market Integration", The Journal of Finance 50, 2, 403-444.

Billio, M and L. Pelizzon, 2000, "Value-at-Risk: A Multivariate Switching Regime Approach", Journal of Empirical Finance 7, 531-554.

Boyson, N., Stahel, C. and R. Stulz, 2006, "Is There Hedge Fund Contagion?", Northeastern University Working Paper.

Brealey, R. and E. Kapalanis, 2001, "Hedge Funds and Financial Stability: An Analysis of Their Factor Exposures," Journal of International Finance 4, 161-187.

Brooks, C. and G. Persand, 2001, "The Trading Profitability of Forecasts of the Gilt-Equity Yield Ratio," Journal of International Forecasting 17, 11-29.

Brown, S. J. and J. F. Spitzer, 2006, "Caught by the Tail: Tail Risk Neutrality and Hedge Fund Returns," Working Paper, New York University.

Chan, N., Getmansky, M., Haas, S. and A. Lo., 2005, "Systemic Risk and Hedge Funds", NBER Book On Risks of Financial Institutions, Topic: Systemic Risk.

Dueker, M. and C.J. Neely, 2004, "Can Markov Switching Models Predict Excess Foreign Exchange Returns?" Federal Reserve Bank of St. Louis Working Paper 2001-021B.

Edwards, F. and M. Caglayan, 2001, "Hedge Fund Performance and Manager Skill," Journal of Futures Markets 21, 1003-1028.

Ferson, W., Kandel, S. and R. Stambaugh, 1987, "Tests of Asset Pricing with Time-Varying Expected Risk Premiums and Market Betas", The Journal of Finance 42, 2, 201-220.

Forbes, K. and R. Rigobon, 2002, "No Contagion, Only Interdependence: Measuring Stock Market Co-Movements", The Journal of Finance 57, 5, 22232261.

Francq, C. and Zakoan, J.-M., 1998, "Estimating Linear Representations of Nonlinear Processes", Journal of Statistical Planning and Inference 68, $145-65$. 
Francq, C. and Zakoan, J.-M., 2001, "Stationarity of Multivariate Markovswitching ARMA Models", Journal of Econometrics 102, 339-64.

Fung, W. and D. Hsieh, 1997a, "Empirical Characteristics of Dynamic Trading Strategies: The Case of Hedge Funds", Review of Financial Studies 10, 275-302.

Fung, W. and D. Hsieh, 1997b, "Investment Style and Survivorship Bias in the Returns of CTAs: The Information Content of Track Records", Journal of Portfolio Management 24, 30-41.

Fung, W. and D. Hsieh, 1999, "A Primer on Hedge Funds", Journal of Empirical Finance 6, 309-31.

Fung, W. and D. Hsieh, 2000, "Performance Characteristics of Hedge Funds and Commodity Funds: Natural versus Spurious Biases", Journal of Financial and Quantitative Analysis 35, 291-307.

Fung, W. and D. Hsieh, 2000, "Measuring the Market Impact of Hedge Funds", Journal of Empirical Finance 7, 1-36.

Fung, W. and D. Hsieh, 2001, "The Risk in Hedge Fund Strategies: Theory and Evidence from Trend Followers", Review of Financial Studies 14, 313341.

Fung, W. and D. Hsieh, 2002a, "Asset-Based Style Factors for Hedge Funds", Financial Analysts Journal 58, 16-27.

Fung, W. and D. Hsieh, 2002b "Benchmarks of Hedge Fund Performance: Information Content and Measurement Biases", Journal of Alternative Investments 58, 22-34.

Fung, W. and D. Hsieh, 2004 "Hedge Fund Benchmarks: A Risk Based Approach", Financial Analyst Journal (Forthcoming).

Garcia, R., 1998 "Asymptotic Null Distribution of the Likelihood Ratio Test in Markov Switching Models", International Economic Review 39, 763-88.

Getmansky, M., Lo, A. and I. Makarov, 2004, "An Econometric Analysis of Serial Correlation and Illiquidity in Hedge-Fund Returns," Journal of Financial Economics 74, 3, 529-610.

Getmansky, M., Lo, A. and S. Mei, 2004, "Sifting Through the Wreckage: Lessons from Recent Hedge-Fund Liquidations", Journal of Investment Management 2, 6-38.

Goetzmann, W., Ingresoll, J., Spiegel, M. and I. Welch, 2006, "Portfolio Performance Manipulation and Manipulation-Proof Performance Measures", Yale University Working Paper. (Previous version of the paper (Sharpening Sharpe Ratios (2002))). 
Guidolin, M. and A., Timmermann, 2006, "International Asset Allocation under Regime Switching, Skew and Kurtosis Preferences", mimeo, Federal Reserve Bank of St. Louis Working Paper 2005-018A.

Gupta, A. and B. Liang, 2005, "Do Hedge Funds Have Enough Capital? A Value at Risk Approach", Journal of Financial Economics 77, 219-253.

Hamilton, J., 1989, "A New Approach to the Economic Analysis of Nonstationary Time Series and the Business Cycle", Econometrica 57, 357-384.

Hansen, B. E, 1992, "The Likelihood Ratio Test Under Non-Standard Conditions: Testing the Markov Switching Model of GNP", Journal of Applied Econometrics 7, 561-582.

Hutchinson, M. and L. Gallagher, 2005, "Convertible Bond Arbitrage", Dublin City University Working Paper.

Hwang, S. and S. Satchell, 2000, "The Disappearance of Style in U.S. Equity Market", Cass Business School Working Paper.

Li, Y. and H. Kazemi, 2006, "Conditional Performance of Hedge Funds: Evidence from Daily Returns", University of Massachusetts, Amherst Working Paper.

Kazemi, H. and T. Schneeweis, 2003, "Conditional Performance of Hedge Funds", University of Massachusetts, Amherst Working Paper.

Krolzig, H.-M., 1997, "Markov-Switching Vector Autoregressions. Modelling, Statistical Inference and Application to Business Cycle Analysis", Lecture Notes in Economics and Mathematical Systems, Volume 454, Berlin: Springer.

Leroux, B. G., 1992, "Consistent Estimation of a Mixing Distribution", Annals of Statistics 20, 1350-60.

Longin, F. 2000, "From Value at Risk to Stress Testing", Journal of Banking and Finance 24, 1097-1130.

Longin, F. and B. Solnik, 2001, "Extreme Correlations of International Equity Markets", The Journal of Finance 56, 2, 649-676.

Mathur, I., Pettengill, G. N. and S. Sundaram, 1995, "The Conditional Relation between Beta and Returns", Journal of Financial and Quantitative Analysis Vol. 30, 1, 101-116.

McFadded, P., 1974, "The Measure of Urban Travel Demand", Journal of Public Economics 303-328.

McLachlan, G. J., 1987, "On Bootstrapping the Likelihood Ratio Test Statistic for the Number of Components in a Normal Mixture", Applied Statistics $36,318-24$. 
Mitchell,M. and T. Pulvino, 2001, "Characteristics of Risk and Return in Risk Arbitrage", The Journal of Finance 56, 6, 2135-2175.

Poskitt, D. S. and Chung, S.-H., 1996, "Markov Chain Models, Time Series Analysis and Extreme Value Theory", Advances in Applied Probability 28, 405-25.

Psaradakis Z. and N. Spagnolo, 2003, "On the Determination of the Number of Regimes in Markov Switching Autoregressive Models", Journal of Time Series Analysis Vol. 24, No. 2.

Sirri, E. and P. Tufano, 1998, "Costly Search and Mutual Fund Flows", The Journal of Finance 53, 1589-1622.

Schneeweis, T., Karavas, V. and G. Georgiev, 2002, "Alternative Investments in the Institutional Portfolio", University of Massachusetts, Amherst Working Paper.

Sharpe, W. F., 1992, "Asset Allocation: Management Style and Performance Measurement", Journal of Portfolio Management 18, 2, 7-19.

Tiwari, A., 2006, "Investing in Mutual Funds with Regime Switching", University of Iowa Working Paper.

Zhang, J. and Stine, R. A., 2001, "Autocovariance Structure of Markov Regime Switching Models and Model Selection", Journal of Time Series Analysis 22, 107-24. 